\title{
A Feedforward Inhibitory Circuit Mediates Lateral Refinement of Sensory Representation in Upper Layer 2/3 of Mouse Primary Auditory Cortex
}

\author{
Ling-yun Li, ${ }^{1,4}$ Xu-ying Ji, ${ }^{1,5}$ Feixue Liang, ${ }^{1,5}$ Ya-tang Li, ${ }^{1,4}$ Zhongju Xiao, ${ }^{5}$ Huizhong W. Tao, ${ }^{1,3}$ and Li I. Zhang ${ }^{1,2}$ \\ ${ }^{1}$ Zilkha Neurogenetic Institute, Departments of ${ }^{2}$ Physiology and Biophysics and ${ }^{3}$ Cell and Neurobiology, ${ }^{4}$ Neuroscience Graduate Program, Keck School of \\ Medicine, University of Southern California, Los Angeles, California 90089, and 'Department of Physiology, School of Basic Medical Sciences, Southern \\ Medical University, Guangzhou 510515, China
}

\begin{abstract}
Sensory information undergoes ordered and coordinated processing across cortical layers. Whereas cortical layer (L) 4 faithfully acquires thalamic information, the superficial layers appear well staged for more refined processing of L4-relayed signals to generate corticocortical outputs. However, the specific role of superficial layer processing and how it is specified by local synaptic circuits remains not well understood. Here, in the mouse primary auditory cortex, we showed that upper L2/3 circuits play a crucial role in refining functional selectivity of excitatory neurons by sharpening auditory tonal receptive fields and enhancing contrast of frequency representation. This refinement is mediated by synaptic inhibition being more broadly recruited than excitation, with the inhibition predominantly originating from interneurons in the same cortical layer. By comparing the onsets of synaptic inputs as well as of spiking responses of different types of neuron, we found that the broadly tuned, fast responding inhibition observed in excitatory cells can be primarily attributed to feedforward inhibition originating from parvalbumin (PV)-positive neurons, whereas somatostatin (SOM)-positive interneurons respond much later compared with the onset of inhibitory inputs to excitatory neurons. We propose that the feedforward circuit-mediated inhibition from PV neurons, which has an analogous function to lateral inhibition, enables upper L2/3 excitatory neurons to rapidly refine auditory representation.
\end{abstract}

Key words: excitatory-inhibitory balance; inhibitory neuron; lateral inhibition; surround suppression; tonal receptive field; whole-cell recording

\section{Introduction}

In all sensory modalities, information is processed vertically along a canonical pathway across cortical layers. Among these cortical layers, the L4 circuits are structured for a faithful recipient of signals conveyed from the thalamus (Winer et al., 2005; Liu et al., 2007; Wu et al., 2008, 2011), whereas the superficial layers appear naturally poised for more refined processing of L4-relayed signals before sending out the principal corticocortical outputs to other cortical areas (Callaway, 1998; Douglas and Martin, 2004). Supporting this view, neuronal selectivity for several sensory features appears more salient in superficial layers than the input layer. For example, in the primate auditory cortex, a large pro-

Received April 14, 2014; revised Aug. 21, 2014; accepted Aug. $27,2014$.

Author contributions: H.W.T. and L.I.Z. designed research; L.-y.L., X.-y.J., F.L., Y.-t.L., and Z.X. performed research; L.-y.L. analyzed data; H.W.T. and L.I.Z. wrote the paper.

This work was supported by National Institutes of Health Grants DC008983 (L.I.Z.) and EY019049 (H.W.T.) and the David and Lucile Packard Foundation (Packard Fellowships for Science and Engineering) (L.I.Z.). Z.X., L.I.Z., and F.L. were also supported by grants from the National Natural Science Foundation of China (U1301225, 31228013, 31200831) and a 973 program (2014CB943002).

Correspondence should be addressed to either of the following: L.I. Zhang, University of Southern California, Health Sciences Campus, ZNI 431, Mail Code 2821, Los Angeles, CA 90089-2821, E-mail: liizhang@usc.edu; or H.W. Tao, University of Southern California, Health Sciences Campus, ZNI 339, Mail Code 2821, Los Angeles, CA 900892821.E-mail: htao@usc.edu.

DOI:10.1523/JNEUROSCI.1516-14.2014

Copyright $\odot 2014$ the authors $\quad 0270-6474 / 14 / 3413670-14 \$ 15.00 / 0$ portion of superficial neurons exhibit enclosed receptive fields, which are strongly selective for sound intensity (Sadagopan and Wang, 2010). In the mouse visual cortex, oriented simple-cell receptive field structures are more pronounced in L2/3 (Liu et al., 2009; Ma et al., 2010), and selectivity for stimulus size is strengthened by specific inhibitory inputs from L2/3 (Adesnik et al., 2012). Compared with the input layer, L2/3 circuits are also found more susceptible to changes induced by alterations of the animal's sensory experience (Trachtenberg et al., 2000; Allen et al., 2003), indicating that the superficial layers play an important role in adapting cortical functions to the external environment.

Despite the functional importance of cortical superficial layers, how information processing and specific response properties are determined in these laminae remains elusive. The strong ascending input from L4 (Barbour and Callaway, 2008; Oviedo et al., 2010), together with the direct input from the thalamus (Petreanu et al., 2009), probably dictates the major functional properties of L2/3 neurons. Conversely, it has been shown in some species that superficial layers contain elaborate horizontal axons (Gilbert and Wiesel, 1983; Callaway and Katz, 1990; White et al., 2001; Marino et al., 2005). The horizontal connections may provide a way of modulating functional responses of neurons in a context-dependent manner (Blakemore and Tobin, 1972; Nelson and Frost, 1978; Allman et al., 1985; Gilbert and Wiesel, 1990; 
Knierim and van Essen, 1992; Levitt and Lund, 1997; Walker et al., 1999), determine the spatial summation of neuronal responses (Hubel and Wiesel, 1965; Sillito and Versiani, 1977; DeAngelis et al., 1994; Li and Li, 1994; Adesnik et al., 2012), or even help to create novel functional properties (Chisum et al., 2003). To understand the logic for hierarchical cortical processing, it is important to elucidate excitatory and inhibitory synaptic circuit mechanisms underlying specific laminar processing. In the mouse primary auditory cortex (A1), by examining the functional responses of excitatory cells and two major types of inhibitory neuron, as well as the innervation patterns between inhibitory and excitatory cells, we found that the upper L2/3 plays a crucial role in refining neuronal selectivity for sound frequency and enhancing contrast of frequency representation. This refinement could be attributed to the feedforward inhibition mediated by parvalbumin (PV) neurons, which contributed to the pronounced lateral suppression observed in the upper L2/3.

\section{Materials and Methods}

Animal preparation and auditory cortical mapping. All experimental procedures used in this study were approved under the Animal Care and Use Committee at the University of Southern California. All animals were housed in a vivarium with a $12 \mathrm{~h}$ light/dark cycle. Experiments were performed in a sound-attenuation booth (Acoustic Systems). Adult female mice (C57BL/6 background, 2-3 months old) were sedated with chlorprothixene $(0.05 \mathrm{ml}$ of $4 \mathrm{mg} / \mathrm{ml})$ and anesthetized with urethane $(1.2 \mathrm{~g} / \mathrm{kg})$. Local anesthesia was applied by administrating bupivacaine subcutaneously. The left auditory cortex of the mouse was exposed, and the ear canal on the same side was plugged with a piece of clay wrapped with a thin layer of cotton. The animal's body temperature was maintained at $37.5^{\circ} \mathrm{C}$ by a feedback heating system (Harvard Apparatus). For auditory stimulation, tone pips ( $100 \mathrm{~ms}$ duration, $3 \mathrm{~ms}$ ramp) of various frequencies $(2-32 \mathrm{kHz}, 0.1$ octave interval) and intensities [seven or eight intensities from $0 \mathrm{~dB}$ sound pressure level (SPL), $10 \mathrm{~dB}$ interval] were generated by a custom software (LabVIEW; National Instruments). Through a 16-bit National Instruments interface, sound was delivered from a calibrated speaker (Tucker-Davis Technologies) to the contralateral ear. The test stimuli were presented in a pseudorandom sequence. We first performed sequential multiunit recordings at an array of cortical sites to identify the location and frequency gradient of the A1. Multiunit spikes were recorded with a parylene-coated tungsten microelectrode (2 $\mathrm{M} \Omega$; FHC) at $250 \mu \mathrm{m}$ below the pia. Electrode signals were amplified (Plexon) and bandpass filtered between 300 and $6000 \mathrm{~Hz}$. A custommade LabVIEW software was used to extract the spike times. The number of tone-evoked spikes was counted within a window of 10-40 ms from the onset of tone stimuli. The characteristic frequency (CF) of the cortical site was determined from the plotted multiunit frequency-intensity tonal receptive field (TRF). A1 was identified by a caudal-to-rostral gradient of CFs (low to high frequency). During the mapping procedure, the cortical surface was slowly perfused with a prewarmed artificial CSF (ACSF; in mm: $124 \mathrm{NaCl}, 1.2 \mathrm{NaH}_{2} \mathrm{PO}_{4}, 2.5 \mathrm{KCl}, 25 \mathrm{NaHCO}_{3}, 20$ glucose, $2 \mathrm{CaCl}_{2}$, and $\left.1 \mathrm{MgCl}_{2}\right)$. After mapping the $\mathrm{Al}$, all the later experiments were performed in the low- to mid-frequency ( $\mathrm{CF} \sim 5-20 \mathrm{kHz}$ ) regions. After the recording, some of the mice were perfused with $4 \%$ paraformaldehyde in PBS, the brain was sectioned, and confocal fluorescence images were taken with an Olympus microscope.

In vivo loose-patch and whole-cell recordings. Loose-patch or whole-cell recordings were performed as described previously (Wu et al., 2006, 2008; Zhang et al., 2011b). We used agar (3.25\%) to minimize cortical pulsation. Neurons recorded at $375-500 \mu \mathrm{m}$ below the pial surface were analyzed for L4 and 150-250 $\mu \mathrm{m}$ for upper L2/3 (Kaur et al., 2005; Oviedo et al., 2010). A small number of cells recorded at depths between 250 and $350 \mu \mathrm{m}$ were analyzed as lower L2/3 cells. The determination of the depths of cortical layers was also based on the distribution of genetically labeled cells in an L4-specific Cre line (Scnn1a-Tg3-Cre; The Jackson Laboratory), as well as that of thalamocortical axons (Fig. 1). Patch pipettes (Kimax) with $\sim 4-5 \mathrm{M} \Omega$ impedance were used. For whole-cell voltage-clamp recordings, the internal solution contained the following: $125 \mathrm{~mm}$ Cs-gluconate, $5 \mathrm{~mm}$ tetraethylammonium-Cl, $4 \mathrm{~mm} \mathrm{MgATP}, 0.3$ mM GTP, 10 mм phosphocreatine, 10 mM HEPES, 1 mM EGTA, 2 mм $\mathrm{CsCl}, 1.5 \mathrm{~mm}$ QX-314, and 1\% biocytin, $\mathrm{pH}$ 7.2. Recordings were made with an Axopatch 200B amplifier (Molecular Devices). The whole-cell and pipette capacitance was completely compensated, and the initial series resistance was compensated for $50-60 \%$ at $100 \mu \mathrm{S}$ lag. Signals were filtered at $2 \mathrm{kHz}$ and sampled at $10 \mathrm{kHz}$. To obtain tone-evoked synaptic responses, neurons were clamped at two different voltages: -70 and 0 $\mathrm{mV}$, which are close to the theoretical reversal potentials for inhibitory and excitatory currents, respectively. For loose-patch and whole-cell current-clamp recordings, pipettes were filled with a potassium-based internal solution: $125 \mathrm{~mm}$ K-gluconate, $4 \mathrm{~mm} \mathrm{MgATP}, 0.3 \mathrm{~mm}$ GTP, 10 mM phosphocreatine, $10 \mathrm{~mm}$ HEPES, 1 mM EGTA, pH 7.2, and $1 \%$ biocytin. Loose-patch recording was performed in a similar way as the whole-cell recording, except that a loose seal $(0.1-0.5 \mathrm{G} \Omega)$ was made on the cell body, allowing spikes only from the patched cell to be recorded. Spike responses were recorded under the voltage-clamp mode, with the command potential adjusted so that a near $0 \mathrm{pA}$ baseline current was achieved. Signals were filtered at $10 \mathrm{kHz}$ and sampled at $10 \mathrm{kHz}$. Spike shape was extracted by superimposing and averaging 50 individual spikes using a custom LabVIEW software. In some experiments, membranes were broken, allowing staining of the recorded cell. The cell morphology was reconstructed with the standard histological procedure for biocytin staining (Hefti and Smith, 2000). As reported previously (Wu et al., 2008; Zhou et al., 2010), patch recordings with large pipette opening sizes resulted in highly biased samplings only from large excitatory neurons. The experimental results in this study also support this notion. We did not ever record from any fast-spiking cell using a recording pipette with $<6 \mathrm{M} \Omega$ impedance. The reconstructed morphologies were also consistent with excitatory cell types (Fig. $1 A, B$ ). The quality of voltage clamp in our recordings was reasonably good, as indicated by the absence of significant excitatory currents when the cell was clamped at $0 \mathrm{mV}$ (Liu et al., 2010; Wu et al., 2011).

In vivo two-photon imaging-guided recording. The $P V$-ires-Cre and SOM-ires-Cre driver lines (The Jackson Laboratory) were crossed with the Ail4 tdTomato reporter line (The Jackson Laboratory) to label desired neurons with fluorescence expression. In vivo two-photon imaging was performed with a custom-built imaging system. A mode-locked titanium:sapphire laser (MaiTai Broadband; Spectra-Physics) was tuned at $880 \mathrm{~nm}$ with the output power at $10-30 \mathrm{~mW}$ for L2/3 neurons. For cell-attached recording, the glass pipette, with $\sim 1 \mu \mathrm{m}$ tip opening and 8-10 M $\Omega$ impedance, was filled with the potassium-based internal solution containing $0.15 \mathrm{~mm}$ calcein (Invitrogen). The pipette tip was navigated in the cortex and patched onto a fluorescent soma as described previously (Liu et al., 2009). After confirming a successful targeting (Liu et al., 2009), the positive pressure in the pipette $(\sim 10 \mathrm{mbar})$ was then released, and a negative pressure (20-150 mbar) was applied to form a loose seal (with $0.1-0.5 \mathrm{G} \Omega$ resistance), which was maintained throughout the course of the recording. The depth of the patched cell (150-250 $\mu \mathrm{m}$ below the pia) was directly determined under imaging. For wholecell recordings, glass pipettes with larger openings ( $6-8 \mathrm{M} \Omega$ impedance) were used to form gigaohm seals on fluorescence-labeled cell bodies. The cell membrane was broken in subsequently, and the recording was made under the current-clamp mode to reveal intracellular membrane potential responses.

Viral injection. AAV2/9.EF1 $\alpha$.DIO.hChR2(H134R)-EYFP.WPRE.hGH (Addegene 20298) virus was injected to the left Al of adult PV-Cre (or $S O M-C r e) \times$ Ail4 tdTomato reporter pigmented female mice, as described previously (Li et al., 2013). Mice were allowed to recover for 2-4 weeks before slice recordings were performed. The same adenoassociated virus (AAV) virus was injected to the center of the ventral medial geniculate body (MGBv; $3.2 \mathrm{~mm}$ caudal to bregma and $2 \mathrm{~mm}$ lateral to middle line at the depth of $3 \mathrm{~mm}$ ) of a few mice to examine the projection pattern of thalamocortical axons in the ipsilateral A1.

Cortical slice preparation. Acute brain slices were prepared from viralinjected mice. After the urethane anesthesia, the animal was decapitated, and the brain was rapidly removed and immersed in an ice-cold dissection buffer (in mM): $60 \mathrm{NaCl}, 3 \mathrm{KCl}, 1.25 \mathrm{NaH}_{2} \mathrm{PO} 4,25 \mathrm{NaHCO}_{3}, 115$ 
A

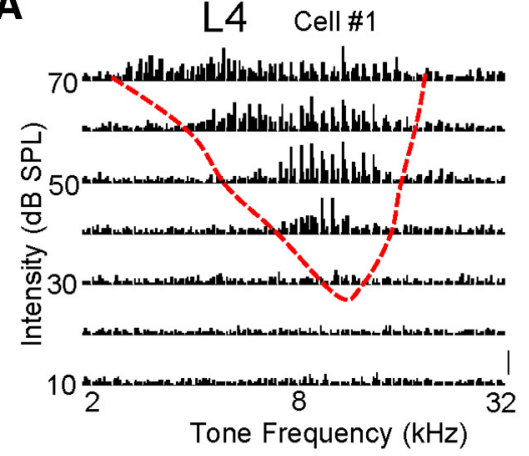

B

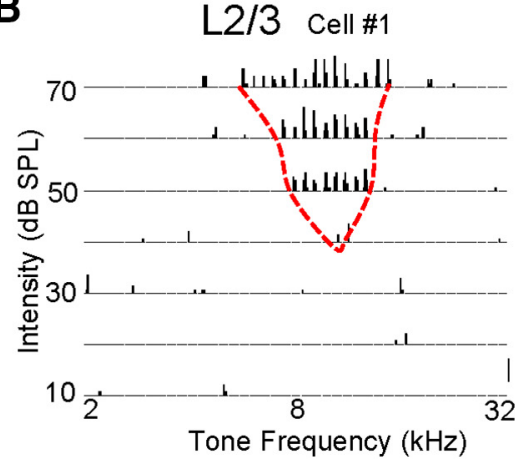

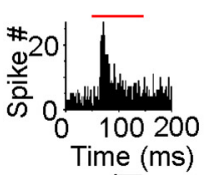

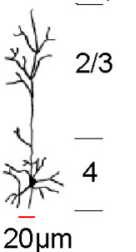

$2 \overline{0} \mu \mathrm{m}$
C
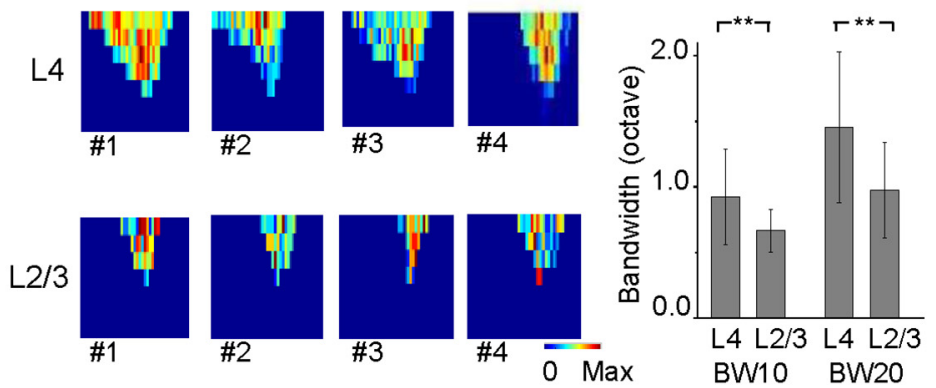

D

BW10 BW20
E

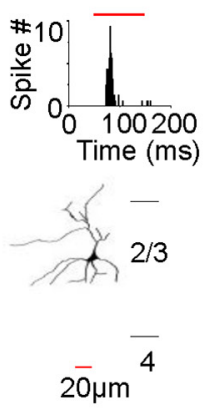

$\mathbf{F}$

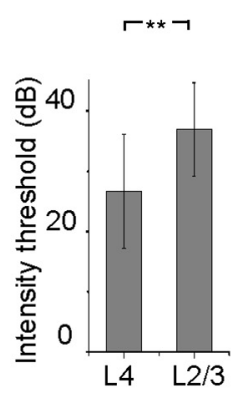

G

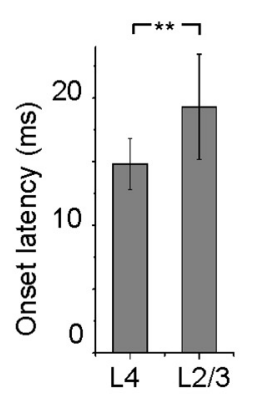

Figure 1. Frequency representation is refined in the upper $L 2 / 3 . A$, Reconstructed spike TRF of an example $L 4$ pyramidal neuron, displayed as an array of PSTHs for the responses of the cell to pure tones of varying frequency and intensity. Red dashed line depicts the TRF boundary. Each PSTH trace depicts the spike response evoked by a $100 \mathrm{~ms}$ tone, averaged over 10 repeats. Bin size, $10 \mathrm{~ms}$. Scale, 0.5 spike count. Right top inset, PSTH generated from the spike responses to all effective tones. Red bar marks the duration of tone stimuli. Right bottom inset, The reconstructed morphology of the cell stained after breaking in the membrane. Cortical layers are marked. $\boldsymbol{B}$, Spike TRFs for an example L2/3 excitatory cell. Data are presented in a similar manner as in $\boldsymbol{A}$. C, More examples of spike TRFs for both $L 4$ and upper $L 2 / 3$ cells. Color maps depict the average evoked spike rate in the frequency-intensity space. Spontaneous activity was subtracted. The color maps in the first column are for the cells shown in $\boldsymbol{A}$ and $\boldsymbol{B}$. Scale: L4, 30, 17, 27 and $23 \mathrm{~Hz}$ for maximum; L2/3, 15, 12, 16 and $20 \mathrm{~Hz}$ for maximum. $\boldsymbol{D}$, Average tuning bandwidths of spike TRF at 10 and $20 \mathrm{~dB}$ above the intensity threshold for L4 $(n=44)$ and L2/3 $(n=29)$ excitatory neurons. Error bar indicates SD. ${ }^{* *} p<0.01, t$ test. $E$, Average intensity thresholds of spike TRF for L4 and L2/3 neurons. ${ }^{* *} p<0.01, t$ test. $\boldsymbol{F}$, Average onset latencies of evoked spike responses. ${ }^{* *} p<0.01, t$ test. $\mathbf{G}$, Left, Confocal image of a coronal section of the A1 of an Scnn1a-Tg3-Cre (L4-specific) tdTomato mouse. Note that fluorescence-labeled neurons are mainly distributed in L4. Scale bar, $100 \mu \mathrm{m}$. Middle, Confocal image showing the distribution of thalamocortical axons, which were labeled by injecting AAV-ChR2-EYFP in the MGBv. WM, White matter. Right, Image showing the MGB injection site. The MGB and A1 are outlined. Scale bar, 1 mm. A, Anterior; P, posterior.

sucrose, 10 glucose, $7 \mathrm{MgCl}_{2}$, and $0.5 \mathrm{CaCl}_{2}$ (bubbled with $95 \% \mathrm{O}_{2}$ and $5 \% \mathrm{CO}_{2}$ ), pH 7.4. Cortical slices of $350 \mu \mathrm{m}$ thickness including the $\mathrm{A} 1$ region were cut in a coronal plane from the infected brain hemisphere using a vibrating microtome (Leica VT1000s). Slices were allowed to recover for $30 \mathrm{~min}$ in a submersion chamber filled with the warmed (at $35^{\circ} \mathrm{C}$ ) ACSF (126 mm NaCl, $2.5 \mathrm{~mm} \mathrm{KCl}, 1.25 \mathrm{~mm} \mathrm{Na}_{2} \mathrm{PO} 4,26 \mathrm{~mm}$ $\mathrm{NaHCO}, 1 \mathrm{~mm} \mathrm{MgCl}_{2}, 2 \mathrm{~mm} \mathrm{CaCl}_{2}, 0.5 \mathrm{~mm}$ ascorbic acid, $2 \mathrm{~mm}$ sodium pyrurate, and $10 \mathrm{~mm}$ glucose, saturated with $95 \% \mathrm{O}_{2}$ and $5 \% \mathrm{CO}_{2}$ ), after which they cooled gradually to the room temperature until recording.

Slice recording. The spatial pattern of hChR2-EYFP expression in each cortical slice was examined under a fluorescence microscope before recording. Only slices with an appropriate viral expression location (within the A1) and spreading range $(\sim 800-1000 \mu \mathrm{m})$ were used for additional recording. Epifluorescence illumination was applied for either specifically targeting td-Tomato and EYFP colabeled inhibitory neurons or avoiding recording from those inhibitory neurons. Patch pipettes with $\sim 4-5 \mathrm{M} \Omega$ impedance were used. For whole-cell voltage-clamp recordings from L2/3 excitatory neurons, the cesium-based internal solution (as described above) was used. The inhibitory synaptic currents were recorded by clamping the membrane potential of the cell at the reversal potential for excitatory synaptic currents $(0 \mathrm{mV})$. For whole-cell currentclamp recordings from PV or SOM neurons, the potassium-based internal solution was used to allow spike generation. Data were recorded with an Axopatch 200B amplifier, filtered at $2 \mathrm{kHz}$, and sampled at $10 \mathrm{kHz}$.

Photostimulation in slice recording. A mercury Arc lamp was used as the light source. The light was delivered through a blue light filter on an upright Olympus microscope (BX51WI), which was collimated and coupled to the epifluorescence pathway of the microscope. A calibrated ap- erture placed at the conjugated plane of the slice was used to control the size of the illumination area. For layer-specific activation, the illuminating spot was restricted to $60-70 \mu \mathrm{m}$ in diameter (power, $0.4 \mathrm{~mW}$ ). For all-layer activation, the illuminating area was large enough to cover the entire A1 region (power, $4 \mathrm{~mW}$ ). A 2-s-long train of $20 \mathrm{~Hz}$ illumination pulses (the duration of each pulse was $1 \mathrm{~ms}$ ) was delivered to test the blue light-evoked responses of viral-infected inhibitory neurons. A 2 ms pulse illumination was used to activate inhibitory neurons while recording from excitatory neurons.

Dynamic-clamp recording. Dynamic-clamp recording under currentclamp mode was performed in L4 and upper L2/3 excitatory neurons in slice preparations. The current injected into the cell was calculated in real time by a custom-written LabVIEW routine and controlled by a National Instrument Interface, as we described previously (Liu et al., 2011; Li et al., 2012):

$$
I(t)=G_{\mathrm{e}}(t) \times\left(V_{\mathrm{m}}(t)-E_{\mathrm{e}}\right)+G_{\mathrm{i}}(t) \times\left(V_{\mathrm{m}}(t)-E_{\mathrm{i}}\right) .
$$

The time-dependent $G_{\mathrm{e}}$ and $G_{\mathrm{i}}$ were similar to those used in the neuron modeling. $E_{\mathrm{e}}$ and $E_{\mathrm{i}}$ were set as 0 and $-70 \mathrm{mV}$, respectively. The membrane potential $V_{\mathrm{m}}$ was sampled at 2 or $5 \mathrm{kHz}$. The junction potential was corrected. Measurements of $V_{\mathrm{m}}$ were corrected offline for the voltage drop on the uncompensated, residual series resistance (15-20 M $\Omega$ ). The corrected $V_{\mathrm{m}}$ was only slightly different from the recorded $V_{\mathrm{m}}$.

Data analysis. In cell-attached recordings, spikes could be detected without ambiguity because their amplitudes were normally higher than $50 \mathrm{pA}$, whereas the baseline fluctuation was $<5 \mathrm{pA}$. Tone-driven spikes were counted within a $0-100 \mathrm{~ms}$ time window after the onset of tones. 
The onset latency of evoked spike response was determined from the peristimulus spike time histogram (PSTH) generated from all the responses as the lag between the stimulus onset and the time point at which spike rate exceeded the baseline level by 3 SDs of the baseline fluctuation. All the synaptic responses were averaged by trials. The peak synaptic responses were analyzed within a $0-100 \mathrm{~ms}$ time window after the tone onset. The onset latency of this averaged trace was identified as the time point in the rising phase of the response waveform, in which the amplitude exceeded the baseline level by 2 SDs of the baseline fluctuation. Only responses with onset latencies within 7-40 $\mathrm{ms}$ from the onset of tone stimulus were considered as evoked.

TRFs were reconstructed according to the array sequence. CF was defined as the frequency that evoked reliable spike responses at the lowest intensity level. TRF bandwidth was measured at 10 and $20 \mathrm{~dB}$ above the intensity threshold (BW10 and BW20, respectively) in cell-attached recordings and at $20 \mathrm{~dB}$ above the intensity threshold (BW20) in whole-cell recordings, as the total frequency range of effective tones. The bandwidth of TRF at $60 \mathrm{~dB}$ SPL was also measured for both spike and synaptic responses. The total responding frequency range was determined based on the continuity of evoked responses in the frequency domain. The boundary of the receptive field was determined as where there were more than two consecutive testing tones in the frequency domain that failed to evoke significant responses. To generate a synaptic tuning curve, an envelope curve was derived based on the peak amplitude of each synaptic response within the total responding frequency range, using a modified MATLAB software, Envelope 1.1 (MathWorks; Sun et al., 2010).

For two-tone stimulation, the first tone was varied in frequency and intensity. The second tone was a CF tone at an intensity of $10-20 \mathrm{~dB}$ above the threshold, which could consistently evoke spike responses. The second tone was played $20 \mathrm{~ms}$ after the onset of the first tone. The method of measuring sideband widths was similar to that described previously (Zhang et al., 2003). The boundary of the suppressive region was determined as the first tone stimulus that suppressed the response evoked by the second tone by half. The inhibitory sideband was calculated as the sum of the lower band (i.e., the frequency range between the lowerfrequency boundaries of the suppressive region and the spike TRF of the cell) and higher band at $20 \mathrm{~dB}$ above the intensity threshold of spike TRF.

Modeling. The synaptic responses in L2/3 excitatory neurons were simulated by the following function (Zhang et al., 2003; Zhou et al., 2010, 2012):

$$
I(t)=a \times H\left(t-t_{0}\right) \times\left(1-e^{-\left(t-t_{0}\right) / \tau_{\text {rise }}}\right) \times e^{-\left(t-t_{0}\right) / \tau_{\text {decay }}} .
$$

$I(t)$ is the modeled synaptic current, $a$ is the amplitude factor, $H(t)$ is the Heaviside step function, $t_{0}$ is the onset delay of excitatory or inhibitory input, and $\tau_{\text {rise }}$ and $\tau_{\text {decay }}$ define the shape of the rising phase and decay of the synaptic current. The $\tau_{\text {rise }}$ (inhibition, $2.57 \mathrm{~ms}$; excitation, $3.92 \mathrm{~ms}$ ) and $\tau_{\text {decay }}$ (inhibition, $60 \mathrm{~ms}$; excitation, $32.96 \mathrm{~ms}$ ) were chosen by fitting the average shape of recorded synaptic responses with the above function. The $t_{0}$ (inhibition, $67.5 \mathrm{~ms}$; excitation, $65.5 \mathrm{~ms}$ ) and $a$ (inhibition, 0.51 or $0.7 \mathrm{nA}$; excitation, $0.35 \mathrm{nA}$ ) were chosen based on our experimental data.

Excitatory and inhibitory synaptic conductances were derived according to the following (Wehr and Zador, 2003; Tan et al., 2004): $I(t)=$ $G_{\mathrm{e}}(t)\left(V(t)-E_{\mathrm{e}}\right)+G_{\mathrm{i}}(t)\left(V(t)-E_{\mathrm{i}}\right)+G_{\mathrm{r}}\left(V(t)-E_{\mathrm{r}}\right) . I$ is the amplitude of current at a given time point, $G_{\mathrm{r}}$ and $E_{\mathrm{r}}$ are the resting conductance and resting membrane potential that could be derived from the baseline recording, $G_{\mathrm{e}}$ and $G_{\mathrm{i}}$ are the excitatory and inhibitory synaptic conductances, respectively, $V$ is the holding voltage, and $E_{\mathrm{e}}(0 \mathrm{mV})$ and $E_{\mathrm{i}}(-70$ $\mathrm{mV})$ are the reversal potentials. In this study, a corrected clamping voltage was used, instead of the holding voltage applied $\left(V_{\mathrm{h}}\right)$. $V(t)$ was corrected by $V(t)=V_{\mathrm{h}}-R s \times I(t)$, where $R s$ was the effective series resistance. A $10 \mathrm{mV}$ junction potential was corrected. By holding the recorded cell at two different voltages, $G_{\mathrm{e}}$ and $G_{\mathrm{i}}$ were calculated from the equation. $G_{\mathrm{e}}$ and $G_{\mathrm{i}}$ reflect the strength of pure excitatory and inhibitory synaptic inputs, respectively.

Membrane potential responses were derived from the simulated excitatory and inhibitory responses based on an integrate-and-fire model (Sun et al., 2010; Zhou et al., 2010):

$$
\begin{aligned}
V_{\mathrm{m}}(t+d t)=-\frac{d t}{C}\left[G_{\mathrm{e}}(t) \times\left(V_{\mathrm{m}}(t)-E_{\mathrm{e}}\right)+\right. & G_{\mathrm{i}}(t) \times\left(V_{\mathrm{m}}(t)-E_{\mathrm{i}}\right) \\
& \left.+G_{\mathrm{r}}\left(V_{\mathrm{m}}(t)-E_{\mathrm{r}}\right)\right]+V_{\mathrm{m}}(t),
\end{aligned}
$$

where $V_{\mathrm{m}}(t)$ is the membrane potential at time $t, C$ the whole-cell capacitance $\left(50 \mathrm{e}^{-12} \mathrm{~F}\right), E_{\mathrm{r}}$ the resting membrane potential $(-65 \mathrm{mV})$, and $G_{\mathrm{r}}$ the resting leaky conductance. $G_{\mathrm{r}}$ was calculated based on the equation $G_{\mathrm{r}}=C \times G_{\mathrm{m}} / C_{\mathrm{m}}$, where $G_{\mathrm{m}}$, the specific membrane conductance, is $2 \mathrm{e}^{-5} \mathrm{~S} / \mathrm{cm}^{2}$ (Stuart and Spruston, 1998), and $C_{\mathrm{m}}$, the specific membrane capacitance, is $1 \mathrm{e}^{-6} \mathrm{~F} / \mathrm{cm}^{2}$ (Hines, 1993; Gentet et al., 2000). To simulate spike responses, a spike was generated when the membrane potential reached at $18 \mathrm{mV}$ above the resting membrane potential (average spike threshold of our recorded cortical cells), and a $5 \mathrm{~ms}$ refractory period was applied. The membrane potential was reset as $5 \mathrm{mV}$ below the spike threshold immediately after the spike (Liu et al., 2010).

Statistics. All data were found to be normally distributed by the Shapiro-Wilk test. Student's $t$ test was used to compare the means of two groups. Paired $t$ test was used to the paired samples, while unpaired $t$ test was applied to independent samples. Data were presented as mean $\pm \mathrm{SD}$ if not otherwise specified.

\section{Results}

\section{Refined frequency representation in a superficial layer}

To reveal the processing role of superficial cortical layers, we compared frequency-intensity TRFs of individual neurons between the thalamocortical recipient L4 and superficial layers in anesthetized adult mouse A1. Cell-attached loose-patch recordings were made in L4 or upper L2/3 of the A1 (see Materials and Methods). The parameters for the recordings were chosen to preferentially record from excitatory neurons (see Materials and Methods). For each neuron, the spike TRF (covering 4 octaves and seven to eight intensities) was mapped for 3-10 trials. As shown by TRF maps of example cells (Fig. $1 A-C$ ), TRFs of the L2/3 neurons were apparently narrower compared with the L4 cells. To quantify the sharpness of TRFs, we measured BW10 and BW20, which was defined as the minimum intensity level at which reliable spike responses were evoked. As summarized in Figure $1 D$, both BW10 and BW20 were larger in the L4 than upper L2/3 neurons, indicating that the latter cells exhibited significantly sharper frequency tuning. In other words, frequency representation has been refined in the upper L2/3. Accompanying with this refinement, the intensity threshold of TRF was also elevated in the upper L2/3 (Fig. 1E). In addition, the spike responses evoked by $\mathrm{CF}$ tones exhibited longer onset latencies in the upper L2/3 than L4 cells (Fig. $1 F$ ), consistent with the direction of primary information flow from L4 to superficial layers (Callaway, 1998; Douglas and Martin, 2004). In this study, the boundaries and locations of cortical layers were verified based on the fluorescence pattern in a transgenic mouse line, Scnn 1a-Tg3$\mathrm{Cre}$, in which fluorescence proteins were specifically expressed in L4 (Fig. $1 G$, left), as well as on the arborization pattern of thalamocortical axons, which were found to be distributed extensively in L1 and L4 (Fig. 1G, middle and right).

The observed TRF refinement in the upper L2/3 could possibly be attributable to excessive cortical inhibition (Ojima and Murakami, 2002; Liu et al., 2010; Sadagopan and Wang, 2010; O'Connell et al., 2011; Zhang et al., 2011a), which has sometimes been measured as the effectiveness of suppressing spikes. Following previous studies (Sutter and Loftus, 2003; Zhang et al., 2003), we evaluated inhibitory regions in the frequency-intensity space with a two-tone stimulation paradigm, which consisted of a CF tone preceded by a testing tone with various combinations of frequency and intensity (see Materials and Methods). Inhibition evoked by a testing tone (masker) could then be reflected by its 
A

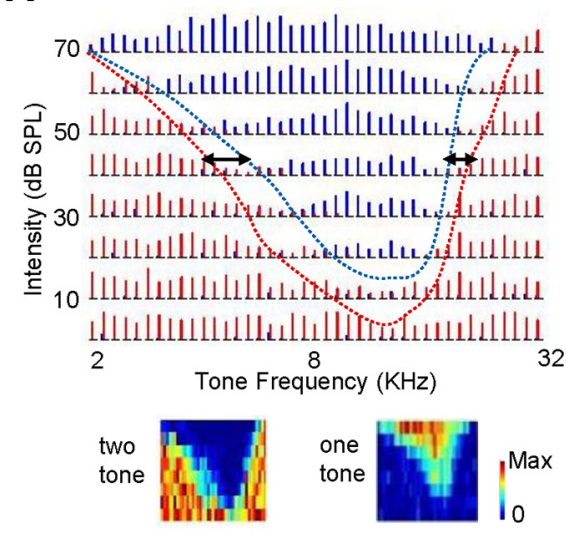

B

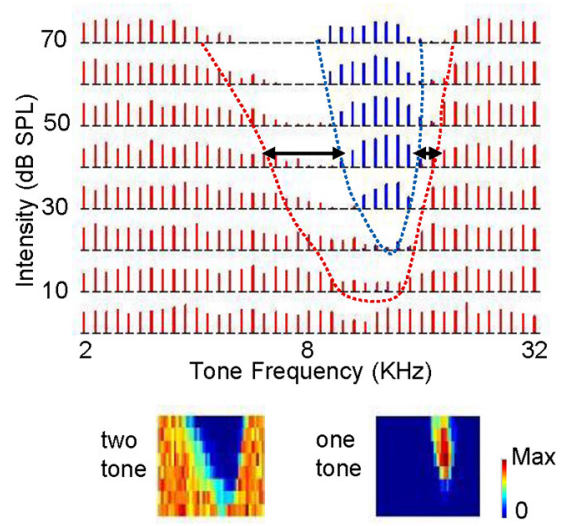

C

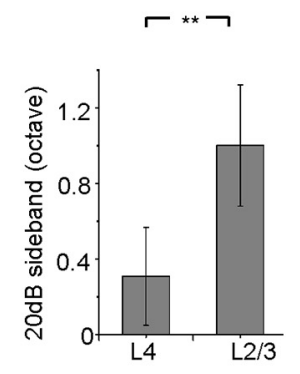

Figure 2. Broader inhibitory sidebands in the upper L2/3 than L4. A, One-tone and two-tone stimulation experiments in an example L4 neuron. Blue, PSTH for the responses to the one-tone stimulation. Red, PSTH for the responses to the two-tone stimulation. Blue curve labels the boundary of the spike TRF of the cell. Red curve labels the boundary of the suppressive region tested with the two-tone stimulation. The interval between the two curves (marked by the double arrowhead) was defined as the inhibitory sideband. Bottom, Color map on the left depicts the suppressive region, and color map on the right depicts the spike TRF of the cell. Scale, 15 and $20 \mathrm{~Hz}$ for maximum. $B$, Spike TRF and suppressive region of an example L2/3 neuron. Data are presented in a similar manner as in A. Scale, 40 and $50 \mathrm{~Hz}$ for maximum. C, Average widths of inhibitory sidebands (quantified at $20 \mathrm{~dB}$ above the TRF intensity threshold) of L4 ( $n=13$ ) and L2/3 ( $n=17$ ) neurons. ${ }^{* *} p<$ $0.01, t$ test.

suppression of the spike response to the CF tone (probe). As shown by two example cells (Fig. $2 A, B$ ), the suppressive region as revealed by two-tone stimulation consisted of two parts: (1) the original spike TRF as demonstrated by one-tone stimulation; and (2) the flanking inhibitory sidebands (Sutter and Loftus, 2003; Zhang et al., 2003). We quantified the absolute width of inhibitory sidebands at $20 \mathrm{~dB}$ above the intensity threshold of TRF (see Materials and Methods). The inhibitory sidebands were significantly broader in the upper L2/3 than L4 neurons (Fig. 2C). Broader inhibitory sidebands would enhance the contrast of TRF edges, increase the signal-to-noise ratio around TRF boundaries, and thus result in better tone discrimination. The sharpening of spike TRF and enhancement of contrast of frequency representation suggested a prominent role of upper L2/3 in refining auditory processing.

\section{Broadly recruited synaptic inhibition in upper $\mathrm{L} 2 / 3$ neurons} However, The broader inhibitory sidebands in the upper L2/3 compared with L4 do not necessarily indicate broader or stronger inhibitory inputs because, in principle, nonlinear spike thresholding effects per se can lead to broader inhibitory sidebands as information is transferred to the next layer of neurons. In addition, the lateral suppression phenomenon itself involves subcortical mechanisms (Kopp-Scheinpflug et al., 2002; Higley and Contreras, 2003; Xie et al., 2007). To further examine potential cortical synaptic mechanisms underlying the observed TRF refinement, we performed in vivo whole-cell voltage-clamp recordings in the A1 (see Materials and Methods). By clamping the membrane potential of the cell at -70 and $0 \mathrm{mV}$, its excitatory and inhibitory synaptic TRFs were revealed separately. Two example cells are shown in Figure $3, A$ and $B$. Although the frequency ranges of inhibitory and excitatory responses looked similar in the L4 cell (Fig. $3 A$ ), the inhibitory TRF was apparently broader than its excitatory counterpart in the upper L2/3 cell (Fig. $3 B$ ). Comparisons of inhibitory and excitatory frequency ranges at the same intensity level are given for more example cells (Fig. $3 C, D$ ). The envelope for peak response amplitudes depicted the frequency tuning curve of synaptic input. As shown by the superimposed inhibitory (black) and excitatory (red) tuning curves (Fig.
$3 C, D$, right), the inhibitory frequency range was broader than the excitatory counterpart in all the example upper L2/3 cells, whereas they were similar in the L4 cells.

We summarized the bandwidth of synaptic tuning, defined as the total frequency range of evoked synaptic responses, at 20 $\mathrm{dB}$ above the intensity threshold of excitatory TRF (i.e., BW20). This intensity level was comparable with that of $10 \mathrm{~dB}$ above the threshold of spike TRF, because the spike TRF threshold was usually $10 \mathrm{~dB}$ higher than the subthreshold TRF threshold (data not shown). The total frequency range of inhibition was significantly broader than that of excitation in the upper L2/3 neurons (Fig. 4A). In contrast, in L4 cells, excitation and inhibition had similar bandwidths (Fig. $4 A$ ), which is consistent with previous reports in the rat A1 (Wu et al., 2008; Sun et al., 2010) and mouse A1 (Tan and Wehr, 2009; Zhou et al., 2014). There was no difference in excitatory frequency range between the upper $\mathrm{L} 2 / 3$ and $\mathrm{L} 4$ cells $(p>0.5, t$ test), whereas the inhibitory frequency range was significantly broader in the upper L2/3 than L 4 cells ( $p<0.05, t$ test). In other words, inhibition was more broadly recruited than excitation in upper L2/3 neurons, which may contribute to their broader inhibitory sidebands compared with $\mathrm{L} 4$ cells. Indeed, in the upper L2/3 cells, the frequency range of synaptic inhibition, measured at $60 \mathrm{~dB}$ SPL, was comparable with the sum of spike response range and inhibitory sideband width (Fig. $4 B)$. This finding suggests that the synaptic inhibition evoked by a preceding tone can contribute to the suppressive region as revealed by two-tone stimulation. Figure $4 C$ shows the distribution of the bandwidth ratio between excitatory and inhibitory frequency ranges across cortical depths of recorded cells. The plot further demonstrates that cells in the upper L2/3 possessed broader inhibition than excitation, whereas cells in the lower L2/3 and L4 exhibited similar bandwidths for excitation and inhibition.

We also examined the temporal relationship between excitatory and inhibitory inputs. As shown in Figure $4 D$, the onset latencies of both excitation and inhibition evoked by bestfrequency $(\mathrm{BF})$ tones were significantly longer in the upper L2/3 than L4 neurons. Consistent with the observation on 
A

L4 Cell \#1

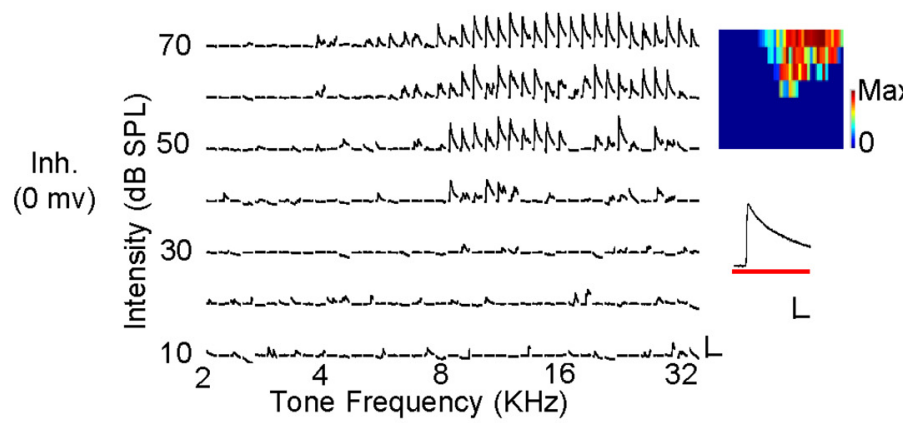

B

L2/3 Cell \#1

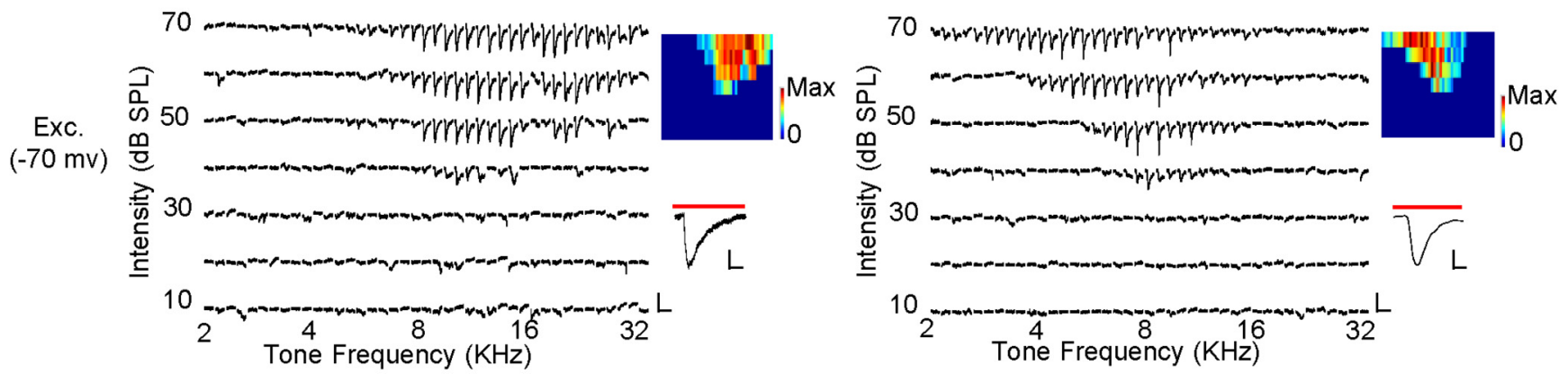

C

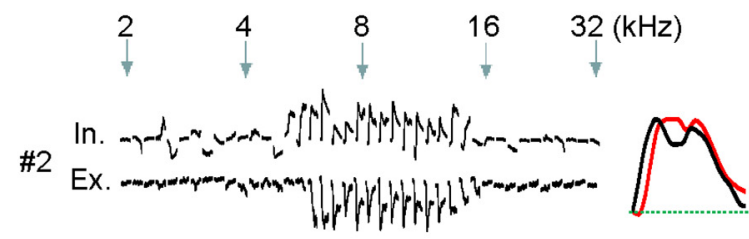

D
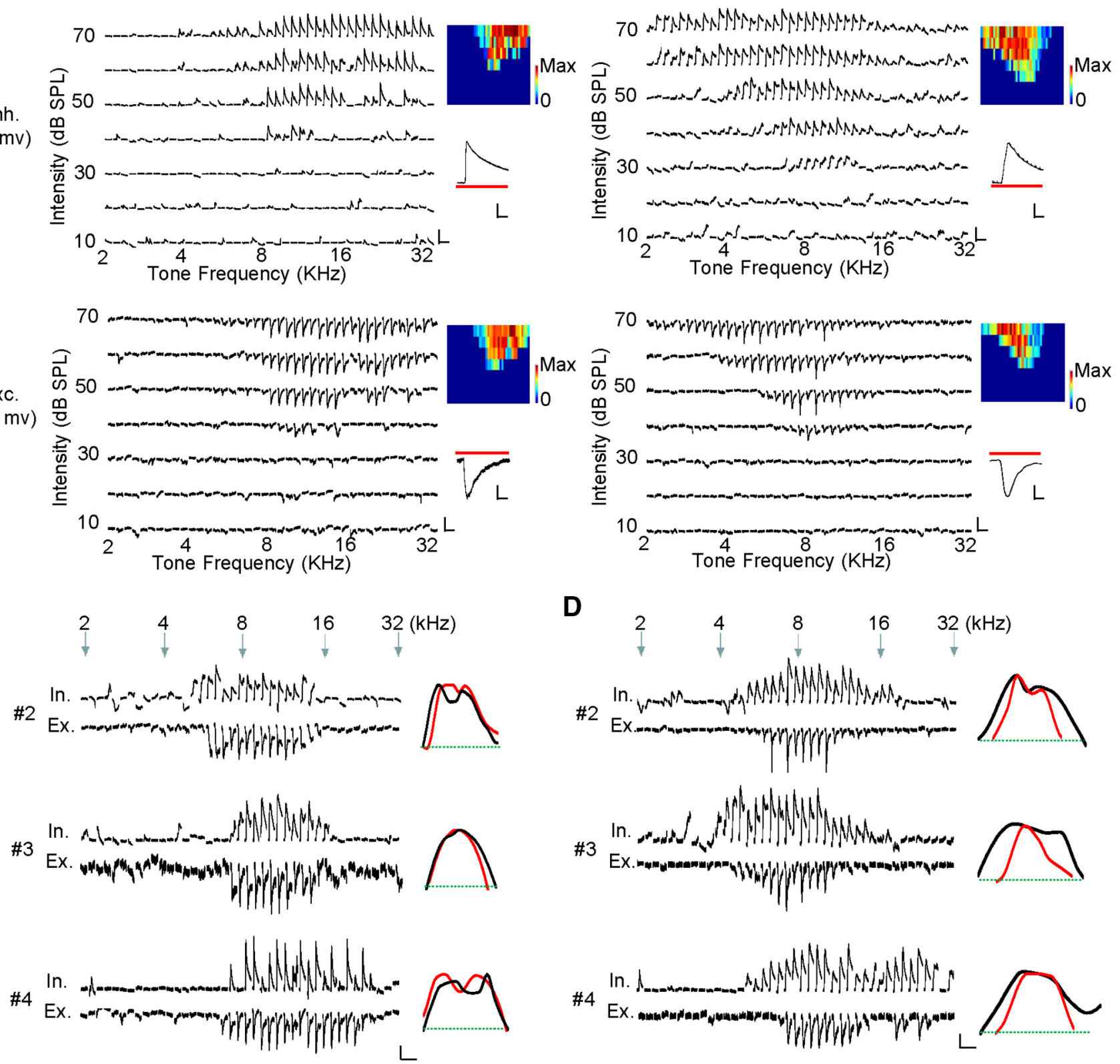

Figure 3. Inhibition has a broader frequency range than excitation in upper $L 2 / 3$ excitatory neurons. $A$, TRFs of inhibitory (upper; Inh) and excitatory (lower; Exc) responses (average of 3 repeats) of an example L4 neuron. Color map depicts the peak response amplitude. Color scale, 414.4 (Inh)/ 249 (Exc) pA. Inset, enlarged response trace to the BF tone at $60 \mathrm{~dB}$ SPL. Red line marks the tone duration (100 ms). Calibration, 120 (Inh)/80 (Exc) pA, 20 ms. B, TRFs of synaptic responses of an example L2/3 cell. Data are presented in a similar manner as in A. Color scale, 715.9 (Inh)/265.2 (Exc) pA. Calibration: 240 (Inh)/90 (Exc) pA, $20 \mathrm{~ms}$. C, Comparison of frequency ranges of inhibitory and excitatory responses at $20 \mathrm{~dB}$ above the intensity threshold of the excitatory TRF for another three L4 cells. Calibration (from top to bottom): 93 (Inh)/49 (Exc), 58/34, and 105/54 pA, 200 ms. Right, Superimposed normalized inhibitory (black) and excitatory (red) tuning curves. Green dotted line labels the baseline. D, Another three L2/3 neurons. Data are presented in a similar manner as in C. Calibration: 95 (Inh)/50 (Exc), 170/32, and 120/39 pA, $200 \mathrm{~ms}$.

spike response (Fig. $1 F)$, this result further supports the notion that this superficial layer receives sensory information later than L4. Within each group of cells, the onset of inhibition was delayed relative to excitation by $2-3 \mathrm{~ms}$ (Fig. $4 D$ ). Such brief delays suggest that the inhibitory input involves one more layer of synaptic relay than the excitatory input. In other words, the inhibition (at least the early component) is feedforward. As for synaptic strength, the upper L2/3 neurons received excitation of a similar amplitude as the L4 cells (Fig. $4 E$ ) but stronger inhibition than the latter (Fig. 4E). This leads to a significantly lower excitation-to-inhibition (E/I) ratio in the upper L2/3 than L4 cells (Fig. 4F; $p<0.05, t$ test). The relatively stronger inhibition can provide additional power to sharpen frequency tuning under a spike thresholding mechanism (Wehr and Zador, 2003; Tan et al., 2004; Zhang et al., 2011a). The temporal response duration, measured at the halfmaximum level, was significantly shorter for excitatory than inhibitory currents in both the L2/3 and L 4 cells (Fig. $4 G ; p<$ 0.01 and $p<0.05$ respectively, $t$ test). In addition, the inhibitory response duration was much longer in the L2/3 than L4 cells (Fig. $4 G$ ), demonstrating that the inhibition in the upper L2/3 cells was temporally more persistent. 
A

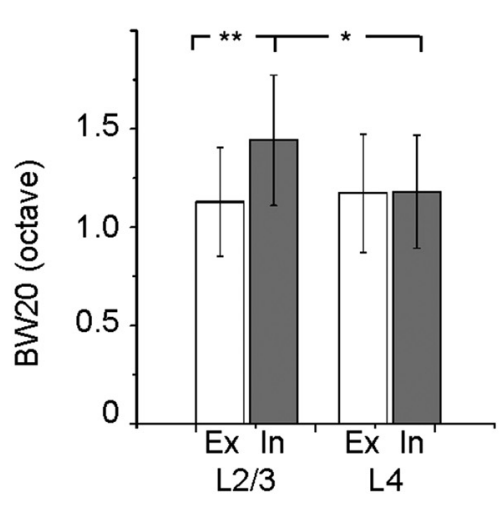

B

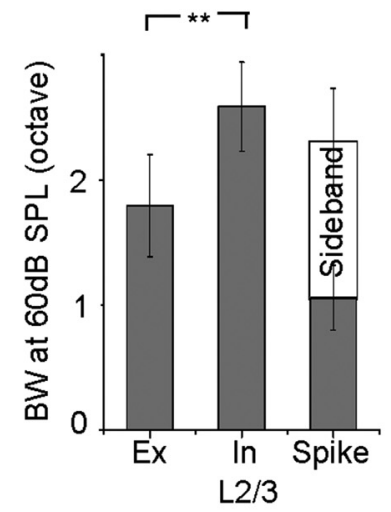

C

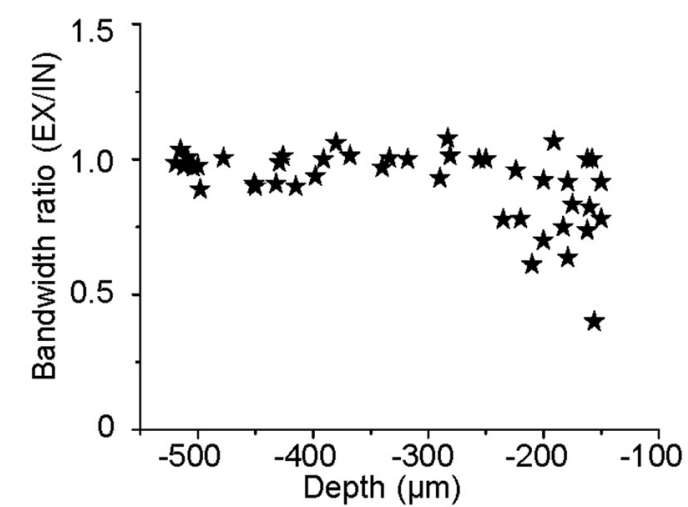

D

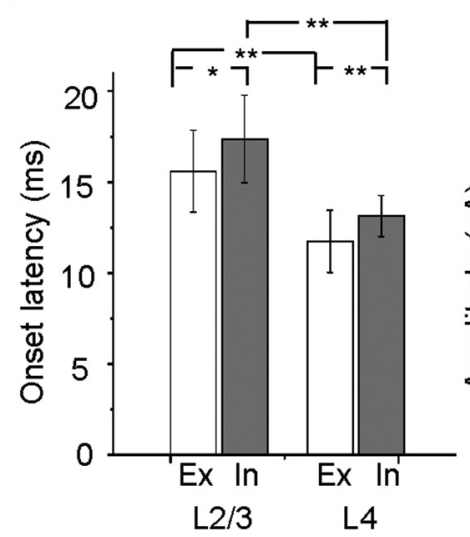

E

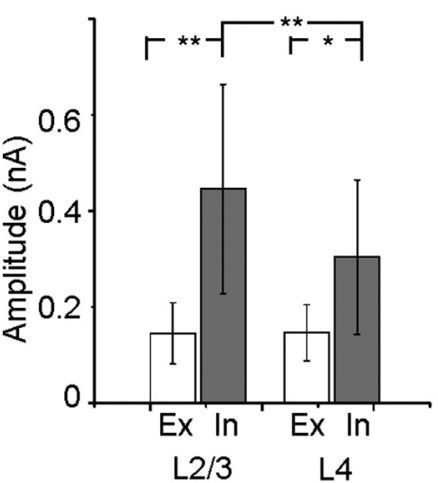

$\mathbf{F}$

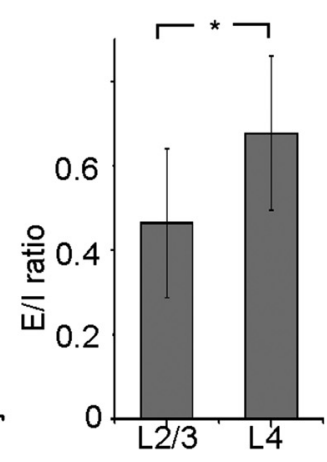

G

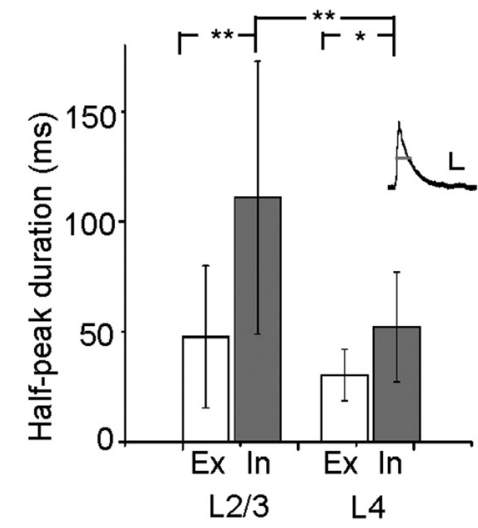

Figure 4. Summary of synaptic response properties for upper $L 2 / 3$ and $L 4$ neurons. $A$, Average frequency bandwidths of excitation and inhibition at $20 \mathrm{~dB}$ above the intensity threshold of the excitatory TRF. $n=19$ for upperL2/3 and 11 for L4. Errorbarindicates SD. ${ }^{*} p<0.05, t$ test; ${ }^{* *} p<0.01$, paired $t$ test. $\boldsymbol{B}$, Average frequency bandwidths at $60 \mathrm{dBSPL}$ for excitation ( $n=19$ ), inhibition $(n=19)$, as well as spike response $(n=29)$ plus inhibitory sideband (white column, $n=17)$ for L2/3 cells. ${ }^{* *} p<0.01$, paired $t$ test. $C$, Plot of bandwidth ratio (E/I) as a function of cortical depth. Bandwidth was measured at $60 \mathrm{~dB}$ SPL as the total frequency range of excitation or inhibition. One data point represents one cell. $D$, Average onset latencies of excitation and inhibition. ${ }^{*} p<0.05$, ${ }^{* *} p<0.01, t$ test. $\boldsymbol{E}$, Average peak amplitudes of excitation and inhibition in response to the BF tone at $60 \mathrm{dBSPL}$. ${ }^{*} p<0.05,{ }^{* *} p<0.01, t$ test. $\boldsymbol{F}$, Average E/I ratios measured for responses at the $B F$ tone of the cell at $60 \mathrm{~dB}$ SPL. ${ }^{*} p<0.05, t$ test. G, Average half-peak durations of excitation and inhibition in response to the BF tone at $60 \mathrm{~dB} S P L$. ${ }^{*} p<0.01$, ${ }^{* *} p<0.05, t$ test. Inset, Sample recorded synaptic response. Red line marks half-peak duration. Calibration: $50 \mathrm{~ms}, 0.1 \mathrm{nA}$.

\section{Sharpening of frequency tuning by broader inhibition}

To understand how the spectral relationship between inhibition and excitation shapes frequency tuning, we applied a conductance-based neuron model to simulate membrane potential $\left(V_{\mathrm{m}}\right)$ responses resulting from synaptic inputs of different tuning patterns (see Materials and Methods). The temporal courses of tone-evoked synaptic inputs in our model were based on the fitting of average $\mathrm{BF}$ tone-evoked synaptic responses (of upper L2/3 cells) in our experimental data (Fig. 5A, left). For simplicity, we only adjusted the spectral relationship between excitatory and inhibitory inputs while fixing other parameters. The E/I ratio was first set at 1:1.5, similar to what was observed in L4 (Fig. 4E). Two scenarios (Fig. $5 A$, right) were compared: (1) cotuned excitation and inhibition as observed in L4; and (2) inhibition having a broader frequency range than excitation as observed in the upper L $2 / 3$. As shown by the derived $V_{\mathrm{m}}$ response traces across frequency (Fig. $5 B$ ) and the envelope of peak $V_{\mathrm{m}}$ responses (i.e., $V_{\mathrm{m}}$ tuning curve; Fig. $5 C$ ), the broader inhibition clearly resulted in sharper $V_{\mathrm{m}}$ response tuning compared with the cotuned inhibition. In addition, the broader inhibition directly generated hyperpolarizing responses at peripheries of the $V_{\mathrm{m}}$ receptive field (Fig. $5 B$, bottom, $C$, right), reminiscent of inhibitory sidebands. We systematically varied the bandwidth of inhibition while fixing that of excitation and measured the half-maximum bandwidth (BW50\%) of the resulting
$V_{\mathrm{m}}$ response tuning. As the bandwidth of inhibition increased, the BW50\% of $V_{\mathrm{m}}$ tuning gradually reduced (Fig. $5 D$ ). Meanwhile, the hyperpolarizing response region became progressively broader (Fig. 5E, black). Reducing the E/I ratio to 1:2 (as observed in upper L2/3 cells) further broadened the hyperpolarizing response region (Fig. 5E, gray). Next we applied a spike thresholding mechanism (Troyer et al., 1998; Liu et al., 2010) to simulate spike responses (Fig. 5F). As expected, spike responses with a narrower frequency range were generated in the broader inhibition scenario compared with the cotuned inhibition (Fig. $5 F, G$ ).

To directly demonstrate the influence of inhibition, it would be important to manipulate the level or tuning of inhibition received by the recorded neuron. Optogenetic inactivation of inhibitory neurons, although an attractive approach, may lead to changes of spike response properties not only by reducing inhibition but also by globally increasing cell excitability and network activity. Considering the potential caveats of optogenetic manipulations, we instead performed dynamic-clamp experiments in which inhibition in the recorded neuron could be controlled in a more specific manner. Dynamic-clamp recordings (Nagtegaal and Borst, 2010; Li et al., 2012) with a $\mathrm{K}^{+}$-based internal solution were performed from L4 and upper L2/3 neurons (see Materials and Methods). We recorded subthreshold membrane potential as well as spike responses to injections of excitatory and inhibi- 
A

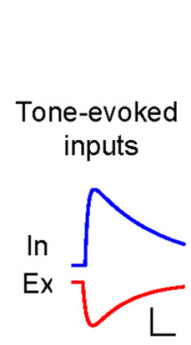

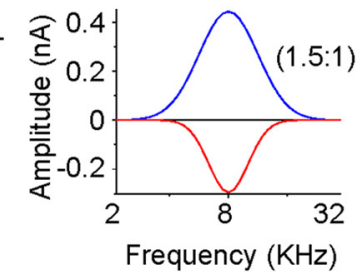

B

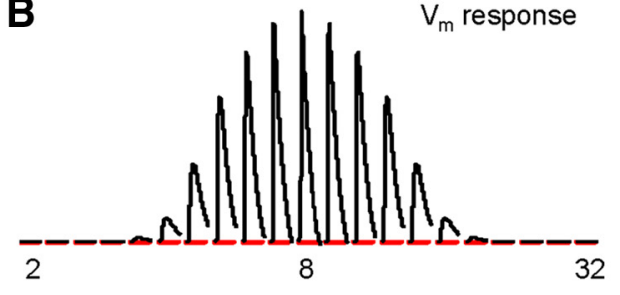

C
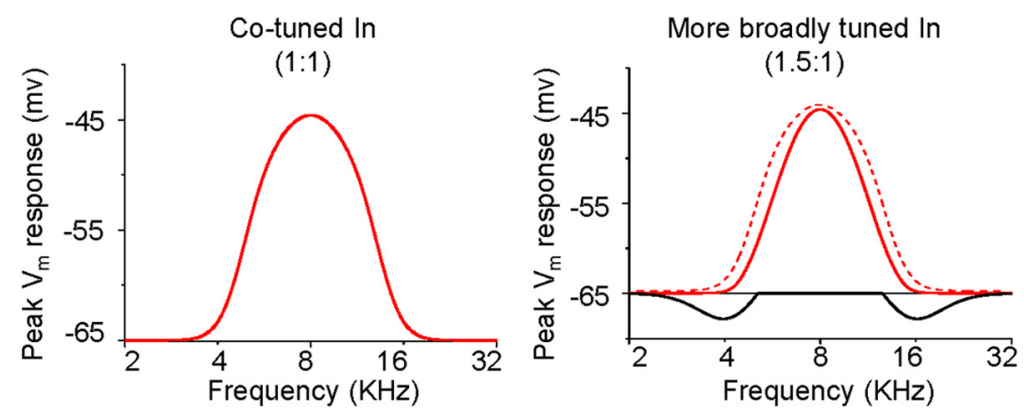

D

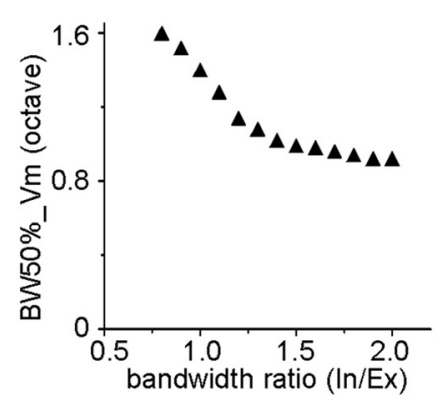

$\mathbf{F}$

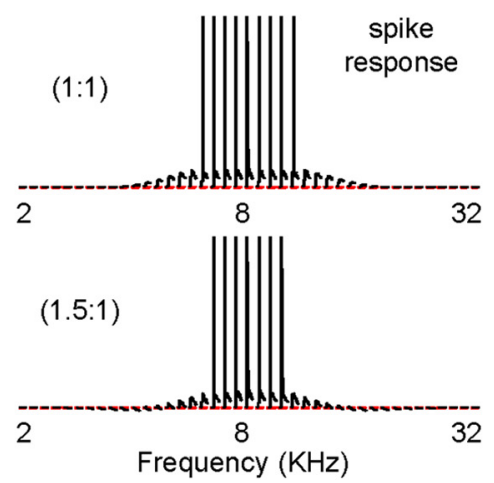

E

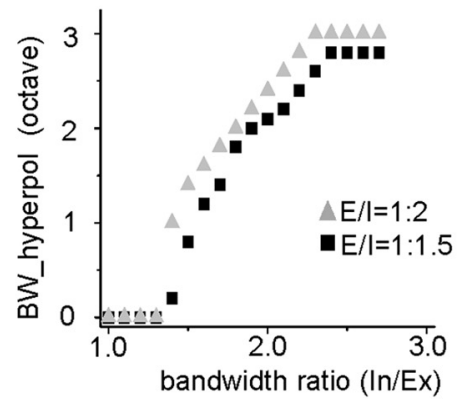

G

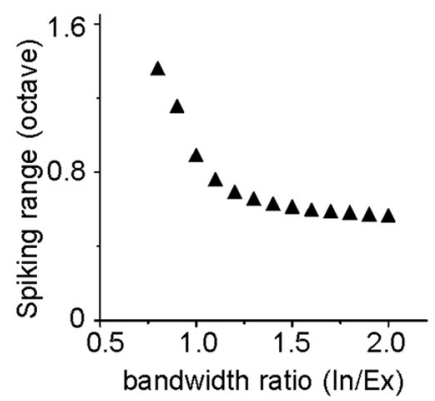

tory conductances as described in Figure 5. Consistent with the neuron modeling results, under the broader inhibition condition, the frequency range of recorded spike responses was narrower compared with the cotuned inhibition condition, regardless of the laminar locations of recorded cells (Fig. 6A,B). Also consistent with the neuron modeling results, hyperpolarizing responses with little depolarization were observed at receptive field peripheries (Fig. 6A, bottom). No significant difference in spike threshold (Fig. 6C) or resting membrane potential (Fig. 6D) was found between L4 and upper L2/3 neurons. In addition, injecting the same set of excitatory and inhibitory conductances into L4 and upper L2/3 neurons generated spike responses with comparable frequency ranges (Fig. $6 \mathrm{~B}$ ), indicating that these two groups of cells did not differ in excitability. Our modeling and dynamic-clamp recording results together support the notion that inhibition having a broader frequency range than excitation can contribute to the generation of inhibitory sidebands and sharpening of frequency tuning.

\section{Sources of inhibitory input to $\mathrm{L} 2 / 3$ excitatory neurons}

Cortical interneurons are the sources of inhibitory input to excitatory cells, and they play important roles in shaping sensory processing (Atallah et al., 2012; Lee et al., 2012; Wilson et al., 2012). To understand how different types of inhibitory neurons might contribute to the broad inhibition and the functional refinement in upper L2/3 excitatory neurons, we first examined the laminar patterns of their innervations of L2/3 excitatory cells in the mouse A1, which are unknown previously. We focused on two major inhibitory neuron types, PV and SOM neurons,

\footnotetext{
curve of peak depolarizing $V_{m}$ responses (red) when inhibition is cotuned with excitation. Right, Frequency tuning curves of peak depolarizing (red) and peak hyperpolarizing (black) $V_{m}$ responses when inhibition is more broadly tuned than excitation. Dotted red curve labels the $V_{\mathrm{m}}$ response tuning in the cotuned scenario. $D, B W 50 \%$ of $V_{m}$ response plotted against the bandwidth ratio (inhibition/excitation). The interval between tones used in the model was 0.01 octave. $\boldsymbol{E}$, Frequency range of hyperpolarizing $V_{\mathrm{m}}$ responses $(>2 \mathrm{mV}$, measured within 50 ms time window after stimulus onset) plotted against the bandwidth ratio (inhibition/excitation). Black and gray represent scenarios when the amplitude ratio $(E / I)$ is 1:1.5 and $1: 2$, respectively. $\boldsymbol{F}$, Frequency tuning of derived spike response under cotuned (upper) or broader (lower) inhibition. Note that each solid vertical line depicts a spike. E/I amplitude ratio, 1:1.5. G, Frequency range of spike response as a function of bandwidth ratio.
}

$\leftarrow$

Figure 5. Modeling of effects of broader inhibition on frequency tuning. $\boldsymbol{A}$, Left, Temporal profiles of modeled tone-ev excitatory (red) and inhibitory (blue) currents. Calibration: $20 \mathrm{~ms}, 0.17 \mathrm{nA}$. The amplitude of inhibition is 1.5 -fold of excitation, and inhibition is delayed by 2 ms relative to excitation. Right, Frequency tuning curves of excitatory (red) and inhibitory (blue) responses. The top panel shows the cotuned (inhibitory/excitatory bandwidth, 1:1) scenario, and the bottom panel shows the broader inhibition (inhibitory/excitatory bandwidth, 1.5:1) scenario. $\boldsymbol{B}$, Traces of derived $V_{\mathrm{m}}$ responses (trace duration, $120 \mathrm{~ms}$ ) across tone frequency in the two scenarios. Red dash line marks the level of resting membrane potential. $\boldsymbol{C}$, Left, Frequency tuning 

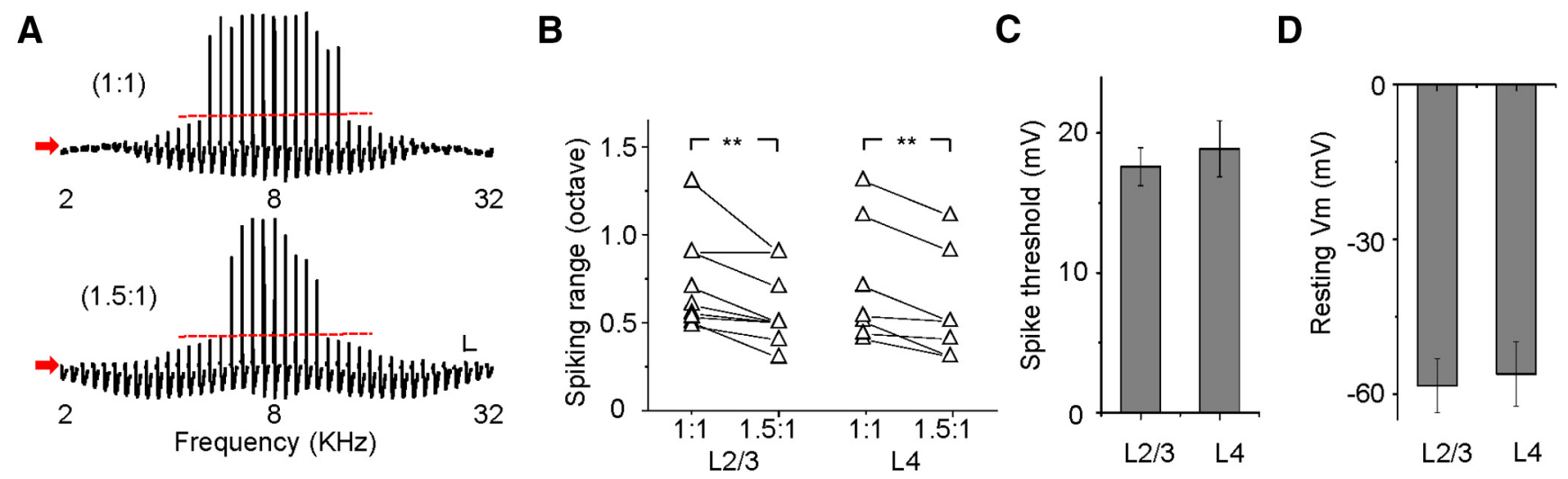

Figure 6. Dynamic-clamp experiment. $A, V_{\mathrm{m}}$ responses of an example cell to injected excitatory and inhibitory conductances simulating responses to different tone frequencies. Top and bottom panels represent the cotuned inhibition and broader inhibition scenarios, respectively. Red dash line marks the level of spike threshold. Arrow points to the level of resting membrane potential. Calibration: $10 \mathrm{mV}, 100 \mathrm{~ms}$. $\boldsymbol{B}$, Comparison of frequency range of recorded spike response under the two scenarios. Data points for the same cell are connected with a line. ${ }^{* *} p<0.01$, paired $t$ test. There is no significant difference between $\mathrm{L} 4$ and $\mathrm{L} 2 / 3$ cells for either condition ( $p>0.05, t$ test). $C$, Comparison of spike threshold (relative to the resting $V_{\mathrm{m}}$ ) between $\mathrm{L} 4$ ( $n=8$ ) and upper $\mathrm{L} 2 / 3$ $(n=14)$ neurons. Data are presented as mean \pm SD. $D$, Comparison of resting $V_{\mathrm{m}}$.

which are known to preferentially target perisomatic and distal dendritic domains of excitatory cells, respectively (Di Cristo et al., 2004). We injected an AAV vector encoding Cre-dependent channelrhodopsin 2 (ChR2) fused with EYFP into the A1 region of $P V$-Cre; $t$ TTomato or SOM-Cre;tdTomato mice (Fig. 7A). After 2-4 weeks, whole-cell recordings were made from fluorescencelabeled PV or SOM neurons in cortical slices prepared from these mice (see Materials and Methods). More than $90 \%$ of tdTomatolabeled PV and SOM neurons in the injected region were expressing ChR2 (Fig. 7A), indicating a high efficiency of viral infection. We found that EYFP-expressing PV and SOM neurons responded reliably with spikes to pulses of blue light applied to the cortical slice (Fig. 7B), confirming the efficiency of ChR2 expression. We locally stimulated inhibitory neurons in each lamina of a cortical column with spatially restricted blue light illumination (spot diameter, 60-70 $\mu \mathrm{m}$; Fig. 7C; see Materials and Methods) and recorded the evoked IPSCs in upper L2/3 excitatory cells in the same column. As shown by two example cells (Fig. 7D), under our experimental conditions, observable IPSCs were evoked only when the circular blue light was applied to L2/3 but not to other layers. The phenomenon occurred in all the recorded L2/3 excitatory cells (Fig. $7 E$ ), indicating that the inhibition to $\mathrm{L} 2 / 3$ excitatory cells primarily originates from inhibitory neurons in the same layer.

Although the optically stimulated PV and SOM neurons were within a similar area around the recorded cell, the amplitude of IPSC evoked by a single pulse of blue light was much larger when PV neurons were stimulated (Fig. $7 D, E$ ). This result is consistent with a slice recording study showing that the individual neuronal contribution of interneuron classes onto excitatory cells is higher for PV than the other inhibitory cell types (Pfeffer et al., 2013). Nonetheless, the total inhibition that can be provided by SOM neurons may not be necessarily smaller than that by PV neurons, because it has been shown in the visual cortex that SOM neurons have a broader range of horizontal innervations of excitatory cells than PV cells (Adesnik et al., 2012). Indeed, when we applied the circular blue light spot at different horizontal positions in L2/3 (Fig. $7 F$ ), the amplitude of IPSC elicited by PV-cell activation quickly reduced as the light spot moved away from the recorded excitatory cell, whereas that of IPSC evoked by SOM-neuron activation reduced much more slowly (Fig. 7G). To compare the total inhibition provided by PV and SOM neurons, we illumi- nated the entire A1 area and thus activated the PV or SOM population to a full extent. We found that the amplitude of total IPSC evoked by PV-cell activation was more than twofold of that by SOM-cell activation (Fig. $7 H ; p<0.05, t$ test). This result suggests that the PV population can potentially provide stronger inhibition than the SOM population.

\section{A major contribution by PV cell-mediated feedforward inhibition}

Based on the comparison of onset latencies of synaptic responses to $\mathrm{BF}$ tones (Fig. $4 \mathrm{C}$ ), we concluded that, at the center of synaptic TRFs, the early-onset inhibition was likely mediated by a feedforward circuit (Zhang et al., 2011b). What about other receptive field regions? To address this issue, we carefully compared the onset latencies of excitation and inhibition across tone frequency. As shown by the responses of an example upper L $2 / 3$ neuron to tones at $60 \mathrm{~dB}$ SPL (Fig. 8A, blue and red), both inhibition and excitation exhibited frequency-dependent changes in onset latency. Latencies were shortest at the receptive field center and increased progressively toward receptive field peripheries. Although the frequency range of inhibition was broader than excitation, within the range in which both excitation and inhibition were evoked, we observed a parallel change of excitatory and inhibitory onset latencies so that their difference (i.e., $\Delta$ latency) remained relatively constant across frequency (Fig. $8 A$, black). Such parallel changes in excitatory and inhibitory onset latencies were observed in all the upper L2/3 excitatory cells recorded, as evidenced by the narrow distribution of $\Delta$ latencies with a mean value of $2.3 \mathrm{~ms}$ (Fig. $8 B$ ). Therefore, within the entire frequency range of excitatory input, there is a nearly constant delay of inhibition relative to excitation, which strongly suggests that the inhibition (at least the early component) is feedforward in nature.

Because inhibitory inputs to L2/3 excitatory cells are mainly from interneurons in the same layer (Fig. $7 E$ ), we performed two-photon imaging-guided targeted loose-patch recordings (Ma et al., 2010; Li et al., 2014) from L2/3 PV and SOM neurons in PV-Cre;tdTomato and SOM-Cre;tdTomato mice, respectively, and compared their spike response onset latencies. As shown by two example cells preferring a similar tone frequency (Fig. 8C), the onset latencies of tone-evoked spikes exhibited a V/U-shaped distribution across tone frequency, similar to that of synaptic inhibition. That is, the latency was shortest at the receptive field 
A

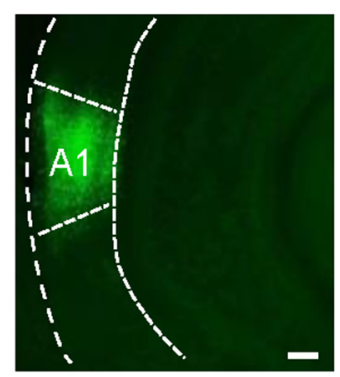

C

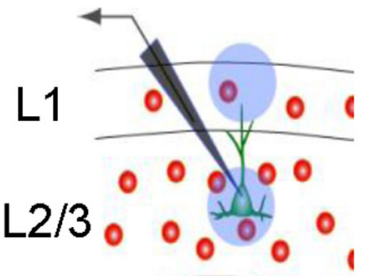

L4 $\frac{0^{\circ} 0^{\circ} 0^{\circ} 0^{\circ}}{0.0000}$

L5 2.0000

L6 0000000

F

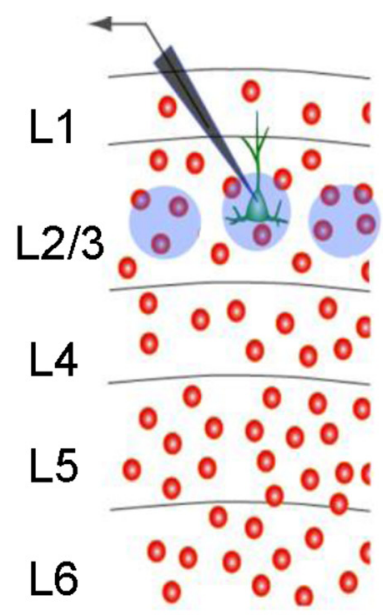

PVChR2

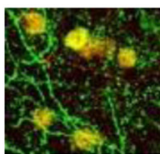

SOMChR2
B

PV

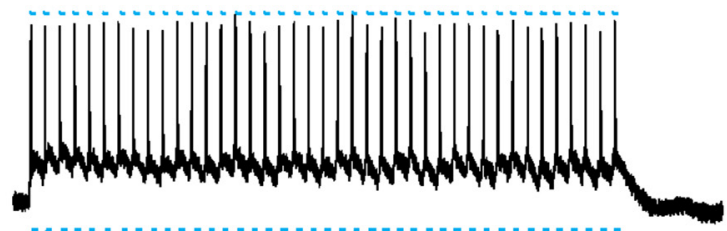

SOM

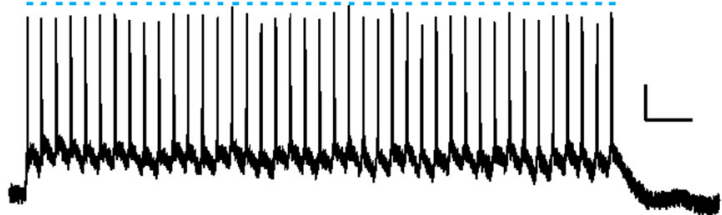

D

L1
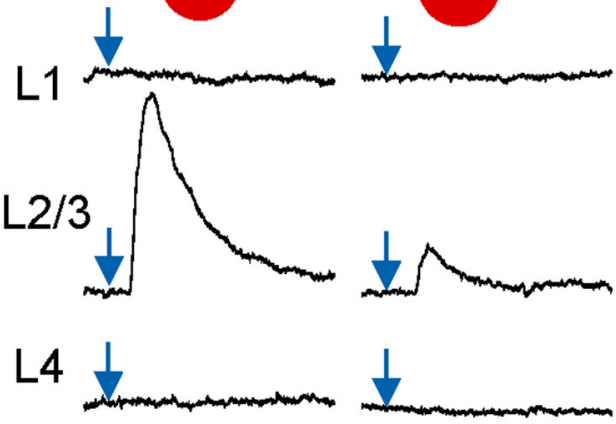

L5

L6

G

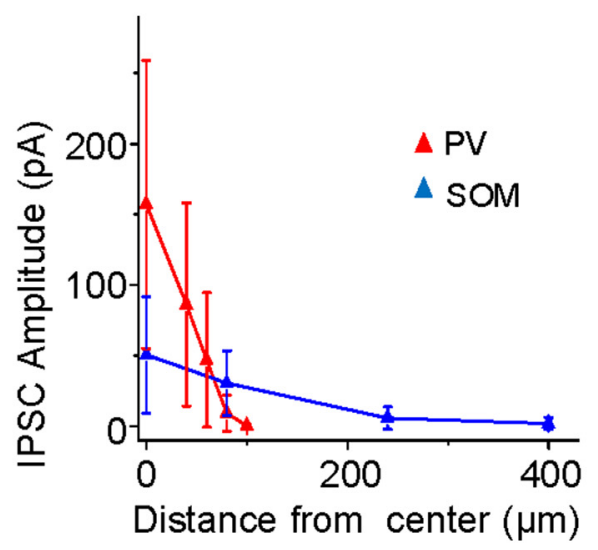

E

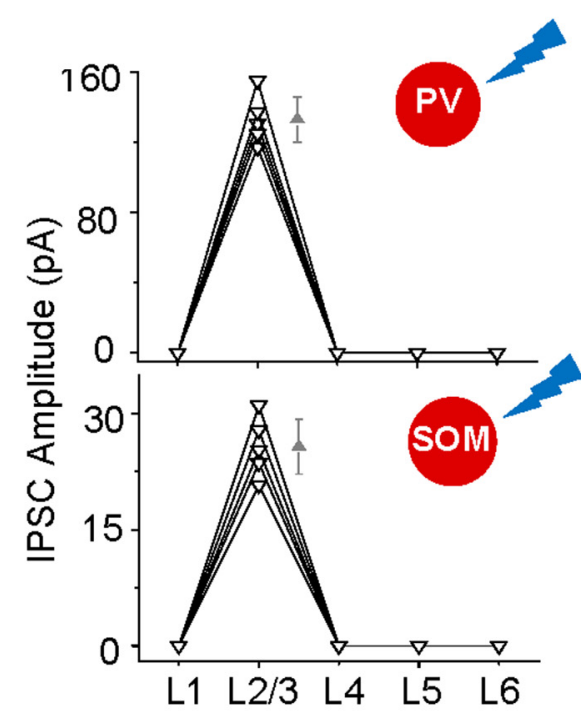

H

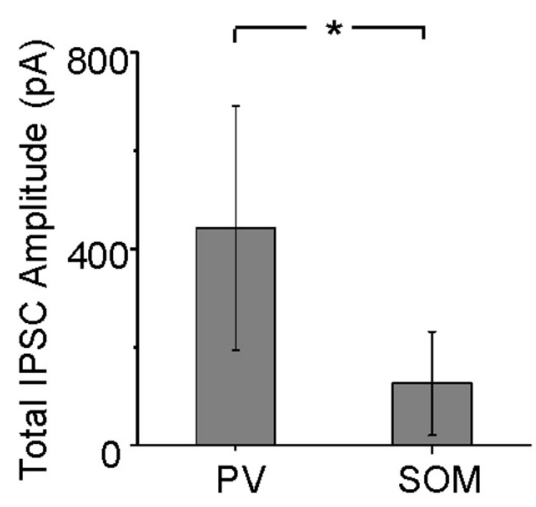

Figure 7. Inhibitory inputs to L2/3 excitatory cells are originated from interneurons in the same layer. A, Left, Confocal image of a brain slice showing that ChR2 was locally expressed in the A1 region. Scale bar, $500 \mu \mathrm{m}$. Right, Enlarged confocal images showing that ChR2-EYFP was expressed in tdTomato-labeled PV (top) or SOM (bottom) neurons. Scale bar, $20 \mu \mathrm{m} . \boldsymbol{B}$, Spikes evoked by $20 \mathrm{~Hz}$ pulses (pulse duration, $1 \mathrm{~ms}$ ) of blue light illumination in an example PV and SOM neuron expressing ChR2, recorded under whole-cell current-clamp mode. Each blue dot indicates a single pulse. Calibration: $20 \mathrm{mV}, 150 \mathrm{~ms}$. C, Schematic graph showing the laminar specific activation of cortical inhibitory neurons. Whole-cell voltage-clamp recording was made from an upper L2/3 excitatory neuron while PV or SOM neurons expressing ChR2 were stimulated by small circular blue light spots (diameter, $60-70 \mu \mathrm{m}$ ). D, IPSCs recorded in an example L2/3 excitatory neuron while activating PV (left) or SOM (right) neurons in different cortical layers. Calibration: 20 pA, $10 \mathrm{~ms}$. E, Average IPSC amplitudes to PV- or SOM-cell activation in different layers for all the recorded L2/3 excitatory neurons $(n=5)$. Data points for the same cell are connected with lines. Gray triangle and bar depict the mean and SD, respectively. $\boldsymbol{F}$, Schematic graph showing the local stimulation of inhibitory neurons in L2/3 in a horizontal plane. G, Average \pm SD IPSC amplitudes to stimulation of PV or SOM neurons at different horizontal distances from the recorded L2/3 excitatory cell $(n=$ 7). $\boldsymbol{H}$, Average \pm SD IPSC amplitudes to stimulation of PV or SOM neurons in the entire A1 region $(n=7) .{ }^{*} p<0.05$, $t$ test. 
A

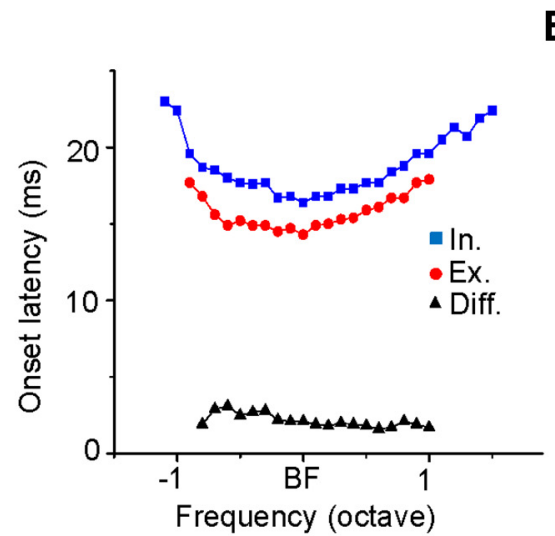

D

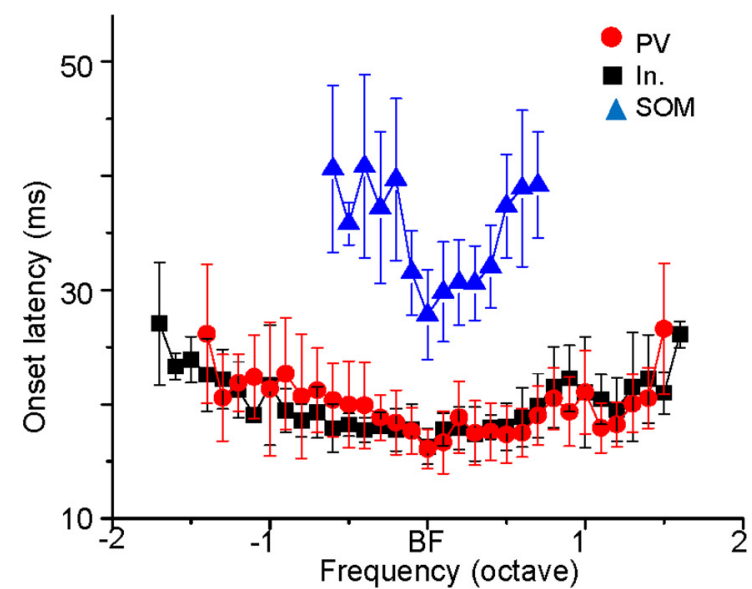

C

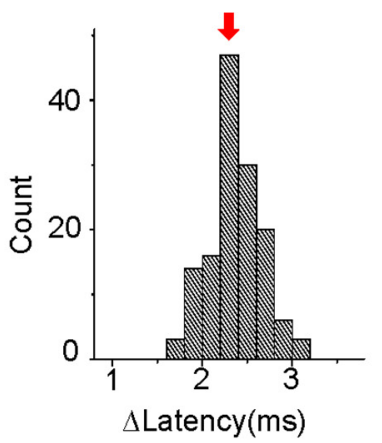

E

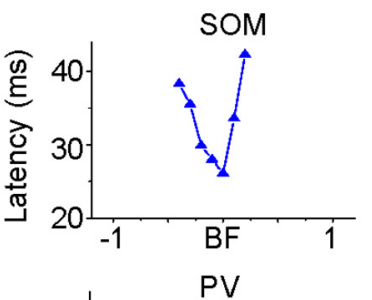

$\sqrt{\frac{1}{2}}$

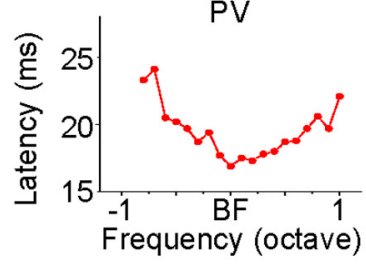

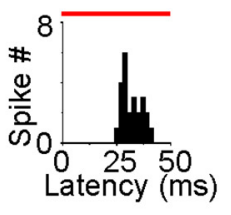

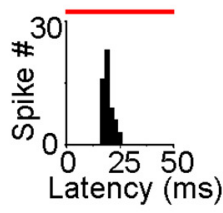

$\mathbf{F}$

$60 \mathrm{~dB}$ SPL, BF

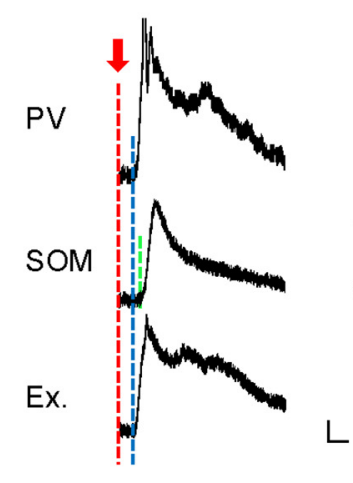

$60 \mathrm{~dB}$ SPL

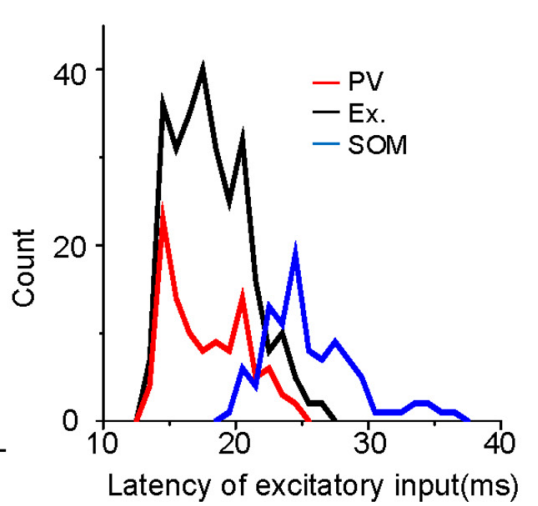

Figure 8. PV neurons mediate the broad inhibition via a feedforward circuit. $\boldsymbol{A}$, Latencies of tone-evoked excitatory (red) and inhibitory (blue) responses at $60 \mathrm{~dB}$ SPL across tone frequency (relative to the BF) in an example L2/3 neuron. Black represents the $\Delta$ latency (inhibition- excitation). B, Distribution of $\Delta$ latencies (to tones at $60 \mathrm{~dB} S P \mathrm{~L}$ ) within the recorded L2/3 excitatory neuron population ( $n=19$ cells). Arrow marks the mean value. $C$, Left, Two-photon image of a td-Tomato-labeled inhibitory neuron in our targeted loose-patch recording (top) and 50 superimposed individual spikes (black) and their average (red) of an example SOM (middle) and PV (bottom) cell. Scale bar (top), $20 \mu \mathrm{m}$. Calibration: $0.6 \mathrm{~ms}, 0.04 \mathrm{nA}$ (middle); $0.6 \mathrm{~ms}, 0.1 \mathrm{nA}$ (bottom). Middle, Latencies of spike responses to $60 \mathrm{~dB}$ tones across frequency for the SOM (upper) and PV (lower) cell. Right, PSTHs of their spike responses. Red bar marks the tone duration. $\boldsymbol{D}$, Average latencies of spike responses to $60 \mathrm{~dB}$ tones across frequency for the recorded SOM (blue, $n=19$ ) and PV (red, $n=17$ ) cells, as well as average latencies of inhibitory responses in the recorded L2/3 excitatory cell population (black, $n=10$ cells). Error bars indicate SD. $E$, Average $V_{m}$ responses to $60 \mathrm{~dB}$ BF tones of an example PV, SOM, and excitatory cell all preferring $8 \mathrm{kHz}$. Note that spikes are truncated. Red, blue, and green dashed lines mark the stimulus onset, the onset of depolarizing responses of the PV and excitatory cells, and the onset of depolarizing responses of the SOM neuron, respectively. Calibration: $4 \mathrm{mV}, 30 \mathrm{~ms}$. F, Distributions of onset latencies of excitatory inputs to the recorded PV (red, $n=8$ cells), SOM (blue, $n=6$ ), and excitatory (black, $n=21$ ) cell populations. Bin size, 1 ms. Latencies were measured for depolarizing $V_{m}$ responses to all effective tones at $60 \mathrm{~dB}$ SPL.

center and longest at receptive field peripheries. Notably, all the spikes of the SOM neuron were delayed relative to the PV cell (Fig. $8 C$, right). Next we compared the onset latencies of SOM and PV-cell spikes with those of synaptic inhibition across frequency. As shown by the summarized result (Fig. 8D), the onset of PV-cell spiking matched well with that of synaptic inhibition (compare red and black), whereas the onset of SOM-neuron spiking (Fig. 8D, blue) was markedly delayed. These data strongly suggest that the onset inhibition in L2/3 excitatory neurons is most likely provided by the PV-cell population. Finally, by breaking the cell membrane, we recorded tone-evoked depolarizing $V_{\mathrm{m}}$ responses in L2/3 excitatory, PV and SOM neurons. As shown by three example cells preferring a similar tone frequency (Fig. $8 E$ ), the onset latency of BF tone-evoked depolarizing response in the PV cell was comparable with that of the excitatory cell. Conversely, the response of the SOM neuron was delayed by several milliseconds. This well explains why the spike responses of SOM neurons were delayed (Fig. $8 D$ ). For summary, we plotted the distribution of onset latencies of depolarizing $V_{\mathrm{m}}$ responses evoked by tones (at $60 \mathrm{~dB}$ SPL) across tone frequency for each recorded cell population (Fig. $8 F$ ). The distributions of excitatory and PV cell populations were similar, whereas the distribution of the SOM population was shifted markedly toward longer latencies. Because the onset latency of the depolarizing $V_{\mathrm{m}}$ response agrees with that of excitatory input, our data indicate that PV cells, like excitatory cells, receive feedforward excitation from lower processing stages, whereas the excitation to SOM cells is more likely from excitatory cells in the same layer (Adesnik et al., 2012). Therefore, the inhibition from L2/3 PV cells is feedforward in nature and is a major mediator underlying the sharpening of TRFs of upper L2/3 excitatory neurons.

\section{Discussion}

In this study, we showed that upper L2/3 excitatory neurons receive a broader frequency range of inhibition than excitation, which contributes to the refining of their frequency tuning. Our results also suggest that this broad inhibition can be primarily attributed to PV neurons recruited via a feedforward circuit.

\section{Lateral suppression in the sensory cortex}

Lateral or surround suppression has been proposed widely to play important roles in sensory processing (Allman et al., 1985; 
Shamma and Symmes, 1985; Gilbert and Wiesel, 1990; Knierim and van Essen, 1992; Levitt and Lund, 1997; Walker et al., 1999). For example, in the visual system, lateral inhibition is thought to increase the contrast and sharpness in visual responses, and surround suppression is shown to underlie neuronal selectivity for stimulus size (Sillito and Versiani, 1977; DeAngelis et al., 1994; Adesnik et al., 2012). In the auditory system, lateral suppression is manifested by the suppression of probe tone-evoked spikes by a masker tone. Although the phenomenon itself involves subcortical mechanisms (Kopp-Scheinpflug et al., 2002; Xie et al., 2007), cortical inhibitory inputs are able to contribute to lateral suppression if the masker tone-evoked inhibition temporally coincides with the probe tone-evoked excitation (Sutter et al., 1999; Ojima and Murakami, 2002). The broader the tone-evoked inhibition in the frequency domain, the larger the suppressive region would appear. Consistent with this concept, we showed here that inhibition being more broadly recruited than excitation in the upper $\mathrm{L} 2 / 3$ contributes to the more pronounced lateral suppression observed in this layer than L4.

\section{Tuning relationship between inhibition and excitation in upper $\mathrm{L} 2 / 3$}

In two recent studies, inhibition being cotuned with excitation has been reported generally for mouse A1 cells, including L2/3 cells (Tan and Wehr, 2009; Zhou et al., 2014), and this has been considered as a universal phenomenon for auditory cortical circuits (Tan and Wehr, 2009). These previous studies only sampled neurons at a deeper laminar location ( $>250 \mu \mathrm{m}$ depth) (Tan and Wehr, 2009; Zhou et al., 2014) than the upper L2/3 $(<250 \mu \mathrm{m}$ depth) defined in this study. Here, using low-angle $\left(25-30^{\circ}\right)$ penetrations, we were able to routinely record from very superficial neurons. Our results are consistent with those previous studies, in that neurons in lower L2/3 and L4 have cotuned excitation and inhibition (Fig. 4C). However, in upper L2/3 neurons, inhibition is broader than excitation. Therefore, although on a global scale excitation and inhibition can be considered as approximately balanced (Isaacson and Scanziani, 2011; Zhang et al., 2011a), the exact tuning relationship between excitation and inhibition may depend on cell type and laminar location. Another interesting example is thick-tufted pyramidal cells in L5 of the rat A1, for which excitation is more broadly tuned than inhibition (Sun et al., 2013).

In rodent sensory cortices, there is no clear anatomical boundary between L2 and L3. Historically, L2/3 has often been considered as a single functional unit. However, a recent study has provided evidence that L2 and L3 neurons may be functionally different (Oviedo et al., 2010). Based on the projection pattern of thalamocortical axons, L3 is also considered as a major input layer in the A1 besides L4 (Winer et al., 2005). Our current results also suggest that functional response properties may be different between upper and lower L2/3 (Fig. 4C), which may approximately correspond to L2 and L3, respectively. Future investigations will be required to identify molecular markers to distinguish between L2 and L 3 in the mouse A1.

\section{Involvement of PV and SOM neurons}

In superficial cortical layers, sensory-evoked inhibition may consist of two components: (1) the feedforward inhibition from inhibitory neurons that are directly activated by ascending axons from lower stages of processing (e.g., L4); and (2) the feedback inhibition indirectly activated by intralaminar horizontal circuits. A visual cortical study has suggested that horizontal connections significantly contribute to the generation of cortical surround suppression in superficial layers (Adesnik et al., 2012). Whether this applies to other sensory cortical areas remains unclear.

One advantage of the auditory cortex is that tone-evoked spike responses are transient onset responses with relatively precise onset timings (with millisecond precision; DeWeese et al., 2003; Zhou et al., 2012). Therefore, based on the timing of spike responses and synaptic inputs, it is possible to delineate the sequence of information flow in cortical circuits comprising different types of neurons (Wu et al., 2011; Li et al., 2014). Because spike timing of the PV neuron population matches the onset timing of synaptic inhibition across stimulus frequency, the PV neuron population most likely contributes to the onset inhibition that is more broadly tuned than excitation. In other words, PV inhibition is most likely able to modulate the generation of onset spike responses in excitatory neurons (Wehr and Zador, 2003; Tan et al., 2004; Zhou et al., 2012) and control the broadness of their spike receptive fields. Conversely, the slow-responding SOM neurons are unlikely able to modulate the onset spike responses, although they may possibly have greater effects on spike responses during more sustained and complicated stimulation.

\section{Feedforward versus feedback inhibition}

The onset delays of synaptic inputs to different types of neurons have shed light on the nature of inhibitory circuits accountable for the broad inhibition observed in upper L2/3 neurons. The excitatory synaptic inputs to L2/3 PV and excitatory cells arrive nearly at the same time (Fig. $8 E$ ), suggesting that these two types of cells both receive ascending inputs from previous processing stages. Therefore, PV neurons are recruited via a feedforward circuit. Some known functional properties of PV cells further put them in the best position to provide broadly tuned inhibition immediately after ascending excitation. First, PV neurons spike even slightly earlier than excitatory neurons (Li et al., 2014), possibly because of a higher efficiency of input-output transformation (Wu et al., 2008). Second, frequency tuning of PV neurons in $\mathrm{L} 2 / 3$ of the A1 has been shown to be much broader than excitatory neurons (Li et al., 2014; but see Moore and Wehr, 2013). Compared with PV and excitatory cells, the excitatory input to SOM neurons is much more delayed, and its timing is more compatible with the spike timing of excitatory neurons (also see Li et al., 2014). These results indicate that SOM neurons are most likely driven by excitatory neurons in the same layer. Therefore, SOM neurons are recruited by horizontal circuits and provide feedback inhibition.

The circuits of PV and SOM neurons found in vivo are consistent with slice recording results in the visual cortex showing that ascending L4 axons provide strong excitation to PV cells in L2/3 but little excitation to SOM neurons in that layer, which otherwise receive strong horizontal excitatory inputs (Adesnik et al., 2012). The broad spatial distribution of SOM-to-excitatory cell connections (Fig. 7G) is also consistent with the visual cortical study. However, different from its conclusion of an important contribution of SOM neurons to size selectivity, our results do not support the idea that SOM neurons can contribute significantly to the sharpness of auditory receptive fields. It is possible that different components of cortical circuits are engaged in different forms of sensory processing, depending on the temporal nature of sensory input (e.g., auditory signals are in general modulated much faster than visual signals). Notably, differential roles of PV and SOM neurons in sensory responses have also been reported in the somatosensory cortex (Gentet et al., 2012) and for 
orientation selectivity in the visual cortex (Atallah et al., 2012; Lee et al., 2012; Wilson et al., 2012).

\section{Potential modulation by brain state}

Our study was performed in anesthetized mice. It remains to be investigated whether the synaptic tuning properties observed here are preserved in awake conditions, considering that the overall $\mathrm{E} / \mathrm{I}$ balance can be modulated by brain states (Bennett et al., 2013; Haider et al., 2013). Interestingly, a recent study in the awake A1 revealed that, when animals transition from quiescence to active behavioral states, excitation and inhibition in lower L2/3 neurons are scaled down by a similar factor, so that the E/I ratio and synaptic tuning properties (frequency range and tuning width) are essentially preserved (Zhou et al., 2014). Whether and how the synaptic response properties in the upper L2/3 are modulated by different behavioral states awaits to be addressed.

Altogether, the refinement of auditory receptive fields in upper L2/3 suggests that the superficial layer does not simply relay L4 signals but performs additional processing of these signals. Powered by broad feedforward inhibition analogous to lateral inhibition, the superficial layer significantly sharpens neuronal selectivity for sound frequency and enhances signal contrast. Besides the broader frequency range for inhibition than excitation, the lower E/I ratio provides an additional mechanism for further narrowing spike receptive fields. The feedforward inhibition mediated by PV neurons not only enables the superficial layer to refine existing neuronal representation of sensory features but may also allow novel representational properties to be created (Sutter and Loftus, 2003; de la Rocha et al., 2008).

\section{References}

Adesnik H, Bruns W, Taniguchi H, Huang ZJ, Scanziani M (2012) A neural circuit for spatial summation in visual cortex. Nature 490:226-231. CrossRef Medline

Allen CB, Celikel T, Feldman DE (2003) Long-term depression induced by sensory deprivation during cortical map plasticity in vivo. Nat Neurosci 6:291-299. CrossRef Medline

Allman J, Miezin F, McGuinness E (1985) Stimulus specific responses from beyond the classical receptive field: neurophysiological mechanisms for local-global comparisons in visual neurons. Annu Rev Neurosci 8:407430. CrossRef Medline

Atallah BV, Bruns W, Carandini M, Scanziani M (2012) Parvalbuminexpressing interneurons linearly transform cortical responses to visual stimuli. Neuron 73:159-170. CrossRef Medline

Barbour DL, Callaway EM (2008) Excitatory local connections of superficial neurons in rat auditory cortex. J Neurosci 28:11174-11185. CrossRef Medline

Bennett C, Arroyo S, Hestrin S (2013) Subthreshold mechanisms underlying state-dependent modulation of visual responses. Neuron 80:350 -357. CrossRef Medline

Blakemore C, Tobin EA (1972) Lateral inhibition between orientation detectors in the cat's visual cortex. Exp Brain Res 15:439-440. Medline

Callaway EM (1998) Local circuits in primary visual cortex of the macaque monkey. Annu Rev Neurosci 21:47-74. CrossRef Medline

Callaway EM, Katz LC (1990) Emergence and refinement of clustered horizontal connections in cat striate cortex. J Neurosci 10:1134-1153. Medline

Chisum HJ, Mooser F, Fitzpatrick D (2003) Emergent properties of layer $2 / 3$ neurons reflect the collinear arrangement of horizontal connections in tree shrew visual cortex. J Neurosci 23:2947-2960. Medline

de la Rocha J, Marchetti C, Schiff M, Reyes AD (2008) Linking the response properties of cells in auditory cortex with network architecture: cotuning versus lateral inhibition. J Neurosci 28:9151-9163. CrossRef Medline

DeAngelis GC, Freeman RD, Ohzawa I (1994) Length and width tuning of neurons in the cat's primary visual cortex. J Neurophysiol 71:347-374. Medline
DeWeese MR, Wehr M, Zador AM (2003) Binary spiking in auditory cortex. J Neurosci 23:7940-7949. Medline

Di Cristo G, Wu C, Chattopadhyaya B, Ango F, Knott G, Welker E, Svoboda K, Huang ZJ (2004) Subcellular domain-restricted GABAergic innervation in primary visual cortex in the absence of sensory and thalamic inputs. Nat Neurosci 7:1184-1186. CrossRef Medline

Douglas RJ, Martin KA (2004) Neuronal circuits of the neocortex. Annu Rev Neurosci 27:419-451. CrossRef Medline

Gentet LJ, Stuart GJ, Clements JD (2000) Direct measurement of specific membrane capacitance in neurons. Biophys J 79:314-320. CrossRef Medline

Gentet LJ, Kremer Y, Taniguchi H, Huang ZJ, Staiger JF, Petersen CC (2012) Unique functional properties of somatostatin-expressing GABAergic neurons in mouse barrel cortex. Nat Neurosci 15:607-612. CrossRef Medline

Gilbert CD, Wiesel TN (1983) Clustered intrinsic connections in cat visual cortex. J Neurosci 3:1116-1133. Medline

Gilbert CD, Wiesel TN (1990) The influence of contextual stimuli on the orientation selectivity of cells in primary visual cortex of the cat. Vision Res 30:1689-1701. CrossRef Medline

Haider B, Häusser M, Carandini M (2013) Inhibition dominates sensory responses in the awake cortex. Nature 493:97-100. CrossRef Medline

Hefti BJ, Smith PH (2000) Anatomy, physiology, and synaptic responses of rat layer $\mathrm{V}$ auditory cortical cells and effects of intracellular GABA(A) blockade. J Neurophysiol 83:2626-2638. Medline

Higley MJ, Contreras D (2003) Nonlinear integration of sensory responses in the rat barrel cortex: an intracellular study in vivo. J Neurosci 23: 10190-10200. Medline

Hines M (1993) NEURON-a program for simulation of nerve equations. In: Neural systems: analysis and modeling (Eeckman F, ed), pp 127-136. New York: Spring.

Hubel DH, Wiesel TN (1965) Receptive fields and functional architecture in two nonstriate visual areas (18 and 19) of the cat. J Neurophysiol 28:229 289. Medline

Isaacson JS, Scanziani M (2011) How inhibition shapes cortical activity. Neuron 72:231-243. CrossRef Medline

Kaur S, Rose HJ, Lazar R, Liang K, Metherate R (2005) Spectral integration in primary auditory cortex: laminar processing of afferent input, in vivo and in vitro. Neuroscience 134:1033-1045. CrossRef Medline

Knierim JJ, van Essen DC (1992) Neuronal responses to static texture patterns in area V1 of the alert macaque monkey. J Neurophysiol 67:961-980. Medline

Kopp-Scheinpflug C, Dehmel S, Dörrscheidt GJ, Rübsamen R (2002) Interaction of excitation and inhibition in anteroventral cochlear nucleus neurons that receive large endbulb synaptic endings. J Neurosci 22:11004-11018. Medline

Lee SH, Kwan AC, Zhang S, Phoumthipphavong V, Flannery JG, Masmanidis SC, Taniguchi H, Huang ZJ, Zhang F, Boyden ES, Deisseroth K, Dan Y (2012) Activation of specific interneurons improves V1 feature selectivity and visual perception. Nature 488:379-383. CrossRef Medline

Levitt JB, Lund JS (1997) Contrast dependence of contextual effects in primate visual cortex. Nature 387:73-76. CrossRef Medline

Li CY, Li W (1994) Extensive integration field beyond the classical receptive field of cat's striate cortical neurons-classification and tuning properties. Vision Res 34:2337-2355. CrossRef Medline

Li LY, Li YT, Zhou M, Tao HW, Zhang LI (2013) Intracortical multiplication of thalamocortical signals in mouse auditory cortex. Nat Neurosci 16:1179-1181. CrossRef Medline

Li LY, Xiong XR, Ibrahim LA, Yuan W, Tao HW, Zhang LI (2014) Differential receptive field properties of parvalbumin and somatostatin inhibitory neurons in mouse auditory cortex. Cereb Cortex. Advance online publication. Retrieved September 3, 2014. doi:10.1093/cercor/bht417. CrossRef

Li YT, Ma WP, Pan CJ, Zhang LI, Tao HW (2012) Broadening of cortical inhibition mediates developmental sharpening of orientation selectivity. J Neurosci 32:3981-3991. CrossRef Medline

Liu BH, Wu GK, Arbuckle R, Tao HW, Zhang LI (2007) Defining cortical frequency tuning with recurrent excitatory circuitry. Nat Neurosci 10: 1594-1600. CrossRef Medline

Liu BH, Li P, Li YT, Sun YJ, Yanagawa Y, Obata K, Zhang LI, Tao HW (2009) Visual receptive field structure of cortical inhibitory neurons revealed by 
two-photon imaging guided recording. J Neurosci 29:10520-10532. CrossRef Medline

Liu BH, Li P, Sun YJ, Li YT, Zhang LI, Tao HW (2010) Intervening inhibition underlies simple-cell receptive field structure in visual cortex. Nat Neurosci 13:89-96. CrossRef Medline

Liu BH, Li YT, Ma WP, Pan CJ, Zhang LI, Tao HW (2011) Broad inhibition sharpens orientation selectivity by expanding input dynamic range in mouse simple cells. Neuron 71:542-554. CrossRef Medline

Ma WP, Liu BH, Li YT, Huang ZJ, Zhang LI, Tao HW (2010) Visual representations by cortical somatostatin inhibitory neurons-selective but with weak and delayed responses. J Neurosci 30:14371-14379. CrossRef Medline

Mariño J, Schummers J, Lyon DC, Schwabe L, Beck O, Wiesing P, Obermayer $\mathrm{K}$, Sur M (2005) Invariant computations in local cortical networks with balanced excitation and inhibition. Nat Neurosci 8:194-201. CrossRef Medline

Moore AK, Wehr M (2013) Parvalbumin-expressing inhibitory interneurons in auditory cortex are well-tuned for frequency. J Neurosci 33: 13713-13723. CrossRef Medline

Nagtegaal AP, Borst JG (2010) In vivo dynamic clamp study of I(h) in the mouse inferior colliculus. J Neurophysiol 104:940-948. CrossRef Medline

Nelson JI, Frost BJ (1978) Orientation-selective inhibition from beyond the classic visual receptive field. Brain Res 139:359-365. CrossRef Medline

O’Connell MN, Falchier A, McGinnis T, Schroeder CE, Lakatos P (2011) Dual mechanism of neuronal ensemble inhibition in primary auditory cortex. Neuron 69:805-817. CrossRef Medline

Ojima H, Murakami K (2002) Intracellular characterization of suppressive responses in supragranular pyramidal neurons of cat primary auditory cortex in vivo. Cereb Cortex 12:1079-1091. CrossRef Medline

Oviedo HV, Bureau I, Svoboda K, Zador AM (2010) The functional asymmetry of auditory cortex is reflected in the organization of local cortical circuits. Nat Neurosci 13:1413-1420. CrossRef Medline

Petreanu L, Mao T, Sternson SM, Svoboda K (2009) The subcellular organization of neocortical excitatory connections. Nature 457:1142-1145. CrossRef Medline

Pfeffer CK, Xue M, He M, Huang ZJ, Scanziani M (2013) Inhibition of inhibition in visual cortex: the logic of connections between molecularly distinct interneurons. Nat Neurosci 16:1068-1076. CrossRef Medline

Sadagopan S, Wang X (2010) Contribution of inhibition to stimulus selectivity in primary auditory cortex of awake primates. J Neurosci 30:73147325. CrossRef Medline

Shamma SA, Symmes D (1985) Patterns of inhibition in auditory cortical cells in awake squirrel monkeys. Hear Res 19:1-13. CrossRef Medline

Sillito AM, Versiani V (1977) The contribution of excitatory and inhibitory inputs to the length preference of hypercomplex cells in layers II and III of the cat's striate cortex. J Physiol 273:775-790. Medline

Stuart G, Spruston N (1998) Determinants of voltage attenuation in neocortical pyramidal neuron dendrites. J Neurosci 18:3501-3510. Medline

Sun YJ, Wu GK, Liu BH, Li P, Zhou M, Xiao Z, Tao HW, Zhang LI (2010) Fine-tuning of pre-balanced excitation and inhibition during auditory cortical development. Nature 465:927-931. CrossRef Medline

Sun YJ, Kim YJ, Ibrahim LA, Tao HW, Zhang LI (2013) Synaptic mechanisms underlying functional dichotomy between intrinsic-bursting and regular-spiking neurons in auditory cortical layer 5. J Neurosci 33:53265339. CrossRef Medline

Sutter ML, Loftus WC (2003) Excitatory and inhibitory intensity tuning in auditory cortex: evidence for multiple inhibitory mechanisms. J Neurophysiol 90:2629-2647. CrossRef Medline

Sutter ML, Schreiner CE, McLean M, O'connor KN, Loftus WC (1999) Organization of inhibitory frequency receptive fields in cat primary auditory cortex. J Neurophysiol 82:2358-2371. Medline
Tan AY, Wehr M (2009) Balanced tone-evoked synaptic excitation and inhibition in mouse auditory cortex. Neuroscience 163:1302-1315. CrossRef Medline

Tan AY, Zhang LI, Merzenich MM, Schreiner CE (2004) Tone-evoked excitatory and inhibitory synaptic conductances of primary auditory cortex neurons. J Neurophysiol 92:630-643. CrossRef Medline

Trachtenberg JT, Trepel C, Stryker MP (2000) Rapid extragranular plasticity in the absence of thalamocortical plasticity in the developing primary visual cortex. Science 287:2029-2032. CrossRef Medline

Troyer TW, Krukowski AE, Priebe NJ, Miller KD (1998) Contrast-invariant orientation tuning in cat visual cortex: thalamocortical input tuning and correlation-based intracortical connectivity. J Neurosci 18:5908-5927. Medline

Walker GA, Ohzawa I, Freeman RD (1999) Asymmetric suppression outside the classical receptive field of the visual cortex. J Neurosci 19:1053610553. Medline

Wehr M, Zador AM (2003) Balanced inhibition underlies tuning and sharpens spike timing in auditory cortex. Nature 426:442-446. CrossRef Medline

White LE, Coppola DM, Fitzpatrick D (2001) The contribution of sensory experience to the maturation of orientation selectivity in ferret visual cortex. Nature 411:1049-1052. CrossRef Medline

Wilson NR, Runyan CA, Wang FL, Sur M (2012) Division and subtraction by distinct cortical inhibitory networks in vivo. Nature 488:343-348. CrossRef Medline

Winer JA, Miller LM, Lee CC, Schreiner CE (2005) Auditory thalamocortical transformation: structure and function. Trends Neurosci 28:255-263. CrossRef Medline

Wu GK, Li P, Tao HW, Zhang LI (2006) Nonmonotonic synaptic excitation and imbalanced inhibition underlying cortical intensity tuning. Neuron 52:705-715. CrossRef Medline

Wu GK, Arbuckle R, Liu BH, Tao HW, Zhang LI (2008) Lateral sharpening of cortical frequency tuning by approximately balanced inhibition. Neuron 58:132-143. CrossRef Medline

Wu GK, Tao HW, Zhang LI (2011) From elementary synaptic circuits to information processing in primary auditory cortex. Neurosci Biobehav Rev 35:2094-2104. CrossRef Medline

Xie R, Gittelman JX, Pollak GD (2007) Rethinking tuning: in vivo wholecell recordings of the inferior colliculus in awake bats. J Neurosci 27: 9469-9481. CrossRef Medline

Zhang LI, Tan AY, Schreiner CE, Merzenich MM (2003) Topography and synaptic shaping of direction selectivity in primary auditory cortex. Nature 424:201-205. CrossRef Medline

Zhang LI, Zhou Y, Tao HW (2011a) Perspectives on: information and coding in mammalian sensory physiology: inhibitory synaptic mechanisms underlying functional diversity in auditory cortex. J Gen Physiol 138:311320. CrossRef Medline

Zhang M, Liu Y, Wang SZ, Zhong W, Liu BH, Tao HW (2011b) Functional elimination of excitatory feedforward inputs underlies developmental refinement of visual receptive fields in zebrafish. J Neurosci 31:5460-5469. CrossRef Medline

Zhou M, Liang F, Xiong XR, Li L, Li H, Xiao Z, Tao HW, Zhang LI (2014) Scaling down of balanced excitation and inhibition by active behavioral states in auditory cortex. Nat Neurosci 17:841-850. CrossRef Medline

Zhou Y, Liu BH, Wu GK, Kim YJ, Xiao Z, Tao HW, Zhang LI (2010) Preceding inhibition silences layer 6 neurons in auditory cortex. Neuron 65:706-717. CrossRef Medline

Zhou Y, Mesik L, Sun YJ, Liang F, Xiao Z, Tao HW, Zhang LI (2012) Generation of spike latency tuning by thalamocortical circuits in auditory cortex. J Neurosci 32:9969-9980. CrossRef Medline 